\title{
Tumor-targeted polymeric nanostructured lipid carriers with precise ratiometric control over dual-drug loading for combination therapy in non-small-cell lung cancer
}

\author{
This article was published in the following Dove Press journal: \\ International Journal of Nanomedicine \\ 2 March 2017 \\ Number of times this article has been viewed
}

\author{
Yan Liang' \\ Baocheng Tian' \\ Jing Zhang' \\ Keke Li' \\ Lele Wang' \\ Jingtian $\mathrm{Han}^{1, *}$ \\ Zimei $\mathrm{Wu}^{2, *}$
}

'School of Pharmacy, Binzhou Medical University, ${ }^{2} \mathrm{School}$ of Pharmacy, Yantai University, Yantai, China

*These authors contributed equally to this work

\begin{abstract}
Gemcitabine (GEM) and paclitaxel (PTX) are effective combination anticancer agents against non-small-cell lung cancer (NSCLC). At the present time, a main challenge of combination treatment is the precision of control that will maximize the combined effects. Here, we report a novel method to load GEM (hydrophilic) and PTX (hydrophobic) into simplex tumor-targeted nanostructured lipid carriers (NLCs) for accurate control of the ratio of the two drugs. We covalently preconjugated the dual drugs through a hydrolyzable ester linker to form drug conjugates. $N$-acetyl-D-glucosamine (NAG) is a glucose receptor-targeting ligand. We added NAG to the formation of NAG-NLCs. In general, synthesis of poly(6-O-methacryloylD-galactopyranose)-GEM/PTX (PMAGP-GEM/PTX) conjugates was demonstrated, and NAG-NLCs were prepared using emulsification and solvent evaporation. NAG-NLCs displayed sphericity with an average diameter of $120.3 \pm 1.3 \mathrm{~nm}$, a low polydispersity index of $0.233 \pm 0.04$, and accurate ratiometric control over the two drugs. A cytotoxicity assay showed that the NAGNLCs had better antitumor activity on NSCLC cells than normal cells. There was an optimal ratio of the two drugs, exhibiting the best cytotoxicity and combinatorial effects among all the formulations we tested. In comparison with both the free-drug combinations and separately nanopackaged drug conjugates, PMAGP-GEM/PTX NAG-NLCs (3:1) exhibited superior synergism. Flow cytometry and confocal laser scanning microscopy showed that NAG-NLCs exhibited higher uptake efficiency in A549 cells via glucose receptor-mediated endocytosis. This combinatorial delivery system settles problems with ratiometric coloading of hydrophilic and hydrophobic drugs for tumor-targeted combination therapy to achieve maximal anticancer efficacy in NSCLC.
\end{abstract}

Keywords: polymer-drug conjugate, nanostructured lipid carriers, combination treatment, ratiometric drug loading, cancer targeting

\section{Introduction}

Recently, nanoparticles (NPs) have attracted much research, due to their ability to reduce nonspecific uptake, prolong drug half-life, and preferentially accumulate in tumors through the enhanced permeation and retention effect. ${ }^{1-3}$ Nanostructured lipid carriers (NLCs) contain solid lipids and liquid lipids, ${ }^{4}$ and present superiority compared to the solid lipid NPs. ${ }^{5-9}$ The addition of spatially incompatible liquid lipids will change the high crystallization from solid lipids. ${ }^{10}$ Obviously, apart from improved bioavailability, loading capacity, and stability, NLCs can still load drugs with different physical and chemical properties, as well as control release. ${ }^{11-13}$ 
The combination of gemcitabine (GEM) plus paclitaxel (PTX) is deemed to be an alternative regimen to platinum drugs for treatment of non-small-cell lung cancer. ${ }^{14-17}$ Although GEM (hydrophilic) interferes with DNA synthesis in the $\mathrm{G}_{0} / \mathrm{G}_{1}$ and $\mathrm{S}$ phases of the cell cycle, ${ }^{18}$ it has a short plasma half-life. PTX (hydrophobic) is a mitotic spindle poison that blocks microtubule disassembly. ${ }^{19}$ Therefore, the rationale for the GEM-PTX combination is supported by their different mechanisms and partially nonoverlapping toxicities. As different ratios of drug combinations may create different effects (synergistic, additive, or antagonistic), fixing ratios to achieve the best cytotoxicity effect and greatest synergy makes sense. ${ }^{20}$ However, the traditional combination drug delivery system, namely the drug cocktail, is limited by the inconsistent biodistribution and pharmacokinetics of drugs and is extremely challenging for treatment optimization..$^{21}$ In order to solve these issues, the present study explored a new approach by covalently conjugating the two drugs at different molar ratios on a macromolecule through hydrolyzable linkers. The galactose-containing copolymer poly(6-O-methacryloyl-D-galactopyranose) (PMAGP) was chosen as the macromolecule. Success in unifying the cellular uptake of dual drugs allows precise control of molar ratios. The ester linkage allows the treatment effect of the hydrophobic and hydrophilic drugs to be resumed after the polymer drugs are delivered into the targeted cells and unloaded from single-vehicle NPs.

What is more, glucose is being applied in drug delivery systems more and more widely. It can promote the delivery of drugs to cancer cells. ${ }^{22}$ As is well-known, the physiological function of cancer cells is different from normal cells. Tumor cells' glucose-metabolism level increases significantly because they are in a hypoxic condition; this is the Warburg effect. ${ }^{23}$ To meet the demand for glucose, tumor cells overexpress glucose transporters. ${ }^{24}$ As a glucose receptor-targeting ligand, $\mathrm{N}$-acetyl-D-glucosamine (NAG) is very innovative and promising. ${ }^{25,26}$

Herein, NAG-NLCs were prepared using emulsification and solvent evaporation. ${ }^{27}$ We showed the synthesis and characterization of PMAGP-GEM/PTX conjugates, and confirmed that the dual-drug conjugates in the NAG-NLCs (Scheme 1A) had controllable drug-to-drug molar ratios. Physicochemical properties of the NAG-NLCs were characterized by size distribution, morphology, and drug-loading efficiency. Then, drug release behavior was confirmed by dialysis. The combinatorial therapy showed better efficacy than both cocktail and separately packaged treatments on cytotoxicity in vitro. Furthermore, we quantified the degree of synergism with the combination index (CI) at $50 \%$ cell kill $\left(\mathrm{CI}_{50}\right)$. Finally, targeted NAG-NLC selective uptake by A549 cells was evaluated, and also suggested that NAGNLCs could be successfully internalized via receptormediated endocytosis (the intracellular performance shown in Scheme 1B).

\section{Materials and methods Materials}

The monomer 6-O-methacryloyl-1,2;3,4-di- $O$-isopropylidene-D-galactopyranose (MaIpG) was synthesized with our previous method. ${ }^{22}$ Succinic anhydride, NAG, PTX, GEM hydrochloride, $N, N^{\prime}$-dicyclohexylcarbodiimide, and 4-dimethylaminopyridine were purchased from Aladdin Biochemical Technology (Shanghai, China). Hoechst 33342, azobisisobutyronitrile, and MTT came from Sigma-Aldrich (St Louis, MO, USA). Fetal bovine serum (FBS), Roswell Park Memorial Institute 1640 medium and trypsinethylenediaminetetraacetic acid were purchased from GE Healthcare (Little Chalfont, UK). Fluorescein isothiocyanate (FITC) was purchased from Fanbo Biochemicals (Beijing, China). Pyridine, acetone, chloroform, $N, N^{\prime}-$ dimethylformamide (DMF), triethylamine, and other chemicals were obtained from local commercial suppliers.

\section{Synthesis of 2'-succinyl-PTX}

2'-Succinyl-PTX was prepared following a published method. ${ }^{28}$ In brief, PTX $(100 \mathrm{mg})$ was dissolved in dry pyridine $(2.5 \mathrm{~mL})$, followed by the addition of succinic anhydride $(150 \mathrm{mg})$. The solution was stirred at ambient temperature for 3 hours and monitored by thin-layer chromatography (TLC) with chloroform/acetone $(15: 1, \mathrm{v} / \mathrm{v})$ as eluent. The retardation factor $\left(\mathrm{R}_{\mathrm{F}}\right)$ of the product was 0.4 . The complete disappearance of the PTX $\left(\mathrm{R}_{\mathrm{F}}=0.6\right)$ occurred after 3 hours of reaction. After the solution had been dried under a vacuum, distilled water $(10 \mathrm{~mL})$ was added and the solution filtrated after stirring. The sediment was dissolved in acetone, water added, and the white solid dried under vacuum. ${ }^{1} \mathrm{H}$ nuclear magnetic resonance (NMR) spectra were recorded on an AM-400 spectrometer (Bruker Optik GmbH, Ettlingen, Germany) using deuterated $\mathrm{CDCl}_{3}$ as the solvent.

\section{Synthesis of 2'-succinyl-GEM}

2'-Succinyl-GEM was synthesized using a previously reported method. ${ }^{29}$ Succinic anhydride $(66.3 \mathrm{mg})$, triethylamine $(31 \mu \mathrm{L})$, and GEM HCl (132 $\mathrm{mg})$ were added to DMF 
A

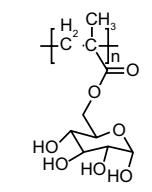

PMAGP
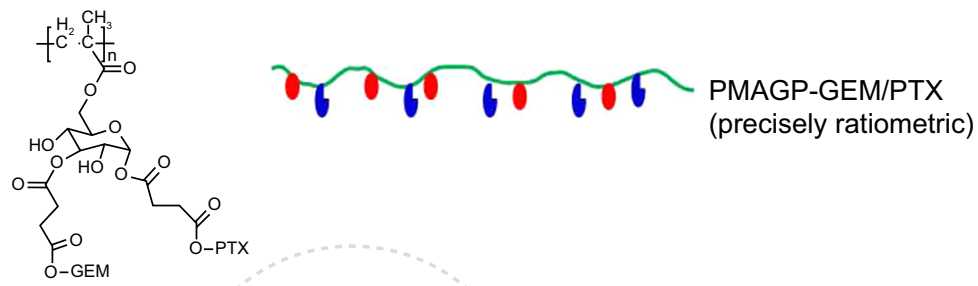

(precisely ratiometric)

- Paclitaxel (hydrophobic drug)

6 Gemcitabine (hydrophilic drug)

$\Delta$ NAG (glucose receptor-targeting ligand)

B

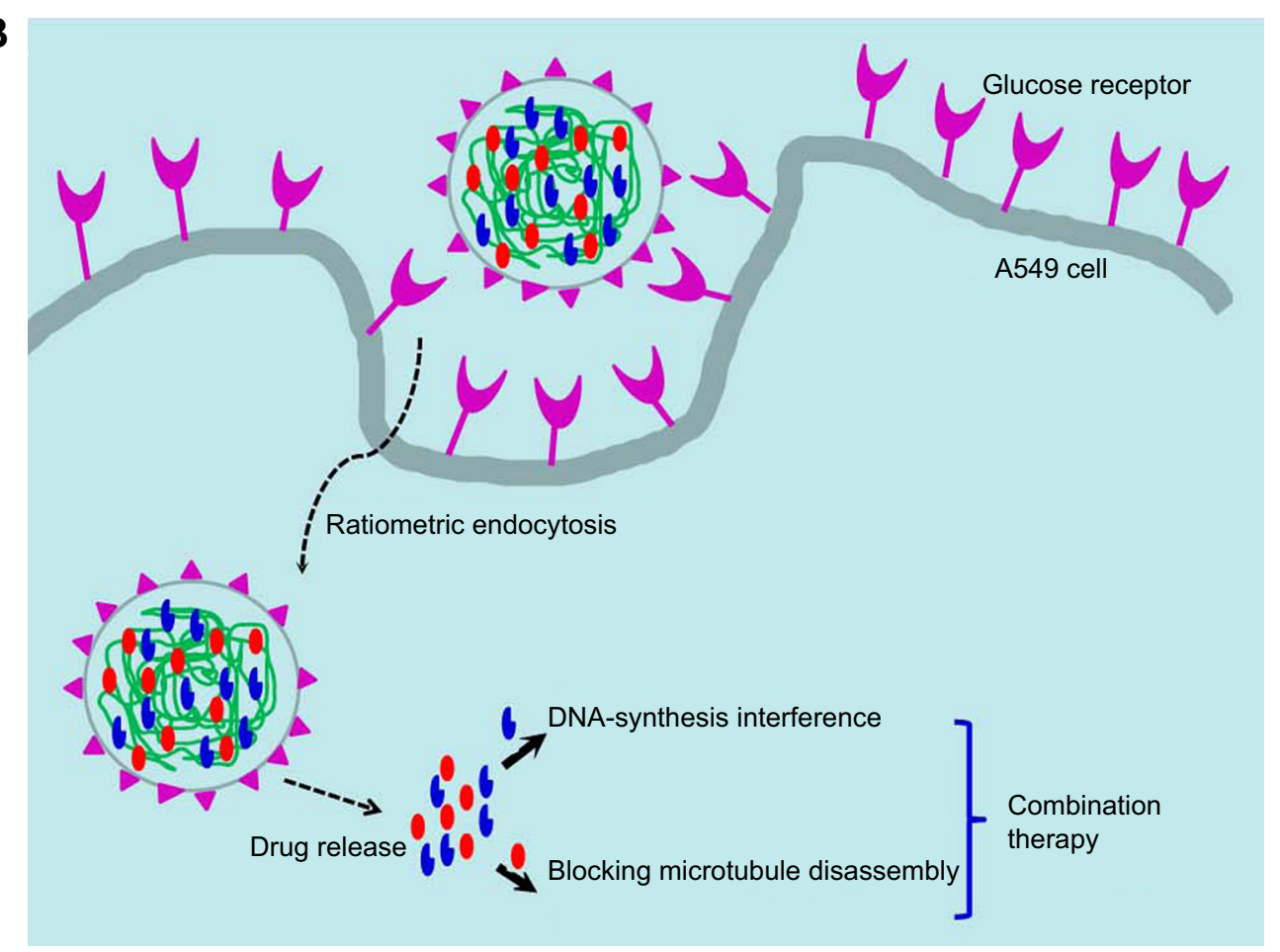

Scheme I Schematic illustration and intracellular performance of dual-drug load NAG-NLCs.

Notes: (A) Dual drug-loaded NAG-NLCs, of which the core consists of two drugs with ratiometric control over drug loading. (B) Intracellular performance of dual drugloaded NAG-NLCs.

Abbreviations: NAG, N-acetyl-D-glucosamine; NLCs, nanostructured lipid carriers; PMAGP, poly(6-O-methacryloyl-D-galactopyranose); GEM, gemcitabine; PTX, paclitaxel. 
(anhydrous). A further $31 \mu \mathrm{L}$ of triethylamine and $22.1 \mathrm{mg}$ of succinic anhydride were added after stirring for 24 hours, and progress was followed by TLC with chloroform/methanol $(2: 1, \mathrm{v} / \mathrm{v})$ as eluent. The $\mathrm{R}_{\mathrm{F}}$ of the product was 0.2 . The GEM $\left(\mathrm{R}_{\mathrm{F}}=0.7\right)$ disappeared after another 24 hours of reaction. Then, the solvent was evaporated under vacuum and the precipitate dissolved in diethyl ether/chloroform $(1: 3, \mathrm{v} / \mathrm{v})$. Finally, the fine residue was obtained by filtrating and subsequently vacuum-drying for 48 hours. The ${ }^{1} \mathrm{H}$ NMR spectra were recorded on an AM-400 spectrometer using dimethyl sulfoxide (DMSO)- $\mathrm{d}_{6}$ as the solvent.

\section{Synthesis of PMAGP}

The MaIpG was prepared as reported previously. ${ }^{22}$ The copolymer PMaIPG was synthesized via reversible additionfragmentation chain-transfer polymerization. Then, for the deprotection of PMaIPG, PMaIPG (200 mg) was dissolved in $80 \%$ methanoic acid $(20 \mathrm{~mL})$ and stirred for 48 hours. Distilled water $(3 \mathrm{~mL})$ was added and stirred for 3 hours. In order to remove methanoic acid, the crude products were purified by dialyzing against distilled water (molecular weight cutoff [MWCO] 4,000 Da). ${ }^{30}$ The pure PMAGP product was obtained using a vacuum freeze-drier (FDU2110; Rikakikai, Tokyo, Japan).

\section{Synthesis of PMAGP-GEM/PTX conjugates}

Defined amounts of 2'-succinyl-PTX, dicyclohexylcarbodiimide $(16.5 \mathrm{mg})$, and PMAGP (100 mg) were dissolved in DMF. The solution was stirred at $70^{\circ} \mathrm{C}$ for 24 hours under an $\mathrm{N}_{2}$ atmosphere. Progress was followed by TLC (chloroform/ acetone, 15:1, v/v). Then, 2'-succinyl-GEM was added for another 24 hours under the same conditions. Progress was also followed by TLC (chloroform/methanol, 2:1, v/v). NLCs with different GEM:PTX drug ratios were obtained by altering the amount of 2 -succinyl-GEM/2'-succinyl-PTX while keeping the total dual-drug moles at $0.3 \mathrm{mmol}$. After cooling, the product was purified by dialyzing against deionized water (MWCO 4,000 Da). PMAGP-PTX/GEM conjugates were collected after freeze-drying. ${ }^{1} \mathrm{H}$ NMR spectra were recorded on an AM-400 spectrometer using deuterated DMSO- $\mathrm{d}_{6}$ as the solvent.

A series of PMAGP-GEM/PTX conjugates were obtained using 2 -succinyl-GEM/2'-succinyl-PTX derivatives at different molar ratios $(5: 1 ; 3: 1 ; 2: 1 ; 1: 1 ; 1: 2 ; 1: 3)$. To label PMAGP-PTX/GEM with FITC, PMAGP-PTX/GEM (50 mg) and FITC (5 mg) were dissolved in dry DMF and stirred for 24 hours. Then, the yellow powder was collected after dialysis against distilled water and freeze-dried.

\section{Preparation of NLCs}

PMAGP-GEM/PTX conjugate-loaded NLCs were obtained using emulsification and solvent evaporation. ${ }^{27}$ PMAGPGEM/PTX conjugates (20 mg), liquid lipid (100 $\mu \mathrm{L})$, glyceryl monostearate $(250 \mathrm{mg})$, NAG $(250 \mathrm{mg})$, soy lecithin $(160 \mathrm{mg})$, and Tween $80(40 \mathrm{mg})$ were dissolved in $3 \mathrm{~mL}$ of methanol and then heated at $70^{\circ} \mathrm{C}$ with continuous stirring. An aqueous surfactant solution with sodium deoxycholate (30 $\mathrm{mg})$ and poloxamer $188(220 \mathrm{mg})$ was prepared at the same time and heated at $70^{\circ} \mathrm{C}$ in another vessel. After the methanol had evaporated completely, the hot aqueous solution was dispersed into the hot-oil phase. The nanoemulsion was stirred for 40 minutes. Then, the obtained samples were immediately cooled to ensure that the NLCs were kept small and stable. After 30 minutes, the dispersion of NLCs was dialyzed (MWCO 100,000 Da) overnight to remove excess drug conjugates and NAG. Finally, a clear PMAGP-GEM/ PTX NAG-NLC solution was obtained subsequent to filtration through a $0.45 \mu \mathrm{m}$ membrane to remove precipitates. The NP suspension was diluted to precise concentration for later experiments. PMAGP-GEM NAG-NLCs, PMAGPPTX NAG-NLCs, and blank PMAGP NAG-NLCs were also obtained, replacing the PMAGP-GEM/PTX. PMAGP-GEM/ PTX NLCs without NAG (PMAGP-GEM/PTX NLCs) was prepared similarly in the absence of NAG.

\section{Stability studies}

To estimate whether NLCs would heavily aggregate when entered into blood circulation, PMAGP-GEM/PTX (3:1) NAG-NLCs were dispersed in double-distilled water, phosphate-buffered saline (PBS), and 10\% (v/v) FBS (in PBS, pH 7.4), respectively, at $37^{\circ} \mathrm{C}$. Size was measured by dynamic light scattering at various time points.

\section{Drug release studies}

To obtain release of PTX and GEM from the PMAGP-GEM/ PTX (3:1) NAG-NLCs at different $\mathrm{pH}$ values, $1 \mathrm{~mL}$ of PMAGP-GEM/PTX NAG-NLC solutions were encapsulated into each membrane dialysis bag (MWCO 6,000-8,000 Da). NLCs were then dialyzed against $40 \mathrm{~mL}$ of $\mathrm{pH} 6$ or $\mathrm{pH}$ 7.4 PBS containing $0.1 \%(\mathrm{w} / \mathrm{v})$ Tween 80 at $37^{\circ} \mathrm{C}$ in a shaker incubator (BS-2F; Zhengji Instruments, Changzhou, China). At each predefined time interval, $4 \mathrm{~mL}$ buffer solution was collected separately for drug quantification and $4 \mathrm{~mL}$ fresh releasing media was added. GEM and PTX amounts were quantified by high-performance liquid chromatography (Agilent 1260) equipped with a $\mathrm{C} 18$ column $(4.6 \times 250 \mathrm{~mm}$ internal diameter, $5 \mu \mathrm{m}$ ) whose mobile phase was acetonitrile and water, and the 
flow rate was $1 \mathrm{~mL} / \mathrm{min}$. The mobile phase of acetonitrile and water $(5: 95, \mathrm{v} / \mathrm{v})$ was employed for the evaluation of GEM, and the detection wavelength was $269 \mathrm{~nm}$. The amount of PTX was quantified using acetonitrile and water (60:40, v/v), and detection wavelength was $227 \mathrm{~nm}$. The retention times of GEM and PTX were 7.678 and 6.575 minutes, respectively.

\section{Cell culture}

The human non-small-cell lung cancer cell lines A549, NCLH1299, and LTEPa2 and the mouse fibroblast L929 cell line were cultured in Roswell Park Memorial Institute 1640 medium. All cells lines were cultured in a humidified incubator at $37^{\circ} \mathrm{C}$ with $5 \% \mathrm{CO}_{2}$ atmosphere.

\section{In vitro cytotoxicity assay and biocompatibility study Biocompatibility study}

The biocompatibility studies of empty PMAGP NAG-NLCs on four types of cancer cell lines were conducted using the MTT assay. L929, A549, NCLH1299, and LTEPa2 cells were seeded at a density of $1 \times 10^{4}$ cells/well in 96-well plates and incubated with empty PMAGP NAG-NLCs $(200 \mu \mathrm{L}$ in RPMI 1640 medium) at different polymer concentrations for 72 hours. Untreated cells acted as controls. Then, MTT was added for another 4 hours at $37^{\circ} \mathrm{C}$. DMSO $(150 \mu \mathrm{L})$ was subsequently added to dissolve the formazan crystals formed. Cell viability was defined as absorbance values at a wavelength of $490 \mathrm{~nm}$ with microplate spectrophotometry (SpectraMax M2, Molecular Devices, Sunnyvale, CA, USA) of samples compared to negative controls. Data are provided as mean \pm standard deviation $(n=6)$.

Cytotoxicity and synergism profiles of free drugs and drug-loaded NLCs

Tumor-cell proliferation-inhibition behaviors of PMAGPGEM/PTX NAG-NLCs (different formulations) and free drugs (different formulations) were evaluated against A549 cells following similar procedures. The total molar concentration of dual drugs from 0.02 to $62.5 \mu \mathrm{mol} / \mathrm{L}$ (the molar concentration was calculated as total free dual drugs) were incubated for 72 hours. $\mathrm{CI}_{50}$ was measured according to Chou's method ${ }^{31}$ :

$$
\mathrm{CI}_{x}=\frac{\mathrm{D}_{1}}{\left(\mathrm{D}_{x}\right)_{1}}+\frac{\mathrm{D}_{2}}{\left(\mathrm{D}_{x}\right)_{2}}
$$

where $\left(\mathrm{D}_{x}\right)_{1}$ and $\left(\mathrm{D}_{x}\right)_{2}$ represent the $\mathrm{IC}_{50}$ value when drug 1 or 2 acts singly. $D_{1}$ and $D_{2}$ represent the concentrations of drug 1 and drug 2 when given as a pair at the $\mathrm{IC}_{50}$ value. Using this method, $\mathrm{CI}_{50}>1$ indicates antagonism, $\mathrm{CI}_{50}=1$ indicates additive, while $\mathrm{CI}_{50}<1$ indicates synergism.

\section{In vitro cytotoxicity analysis}

The antitumor activity of free GEM:PTX (3:1), PMAGPGEM NAG-NLCs + PMAGP-PTXNAG-NLCs (Combo NPs) (3:1), and PMAGP-GEM/PTX (3:1) conjugate-loaded NAGNLCs and PMAGP-GEM/PTX (3:1) conjugate-loaded NLCs in A549, NCLH1299, and LTEPa2 cells, respectively, were investigated as per the aforementioned method. The total dual-drug molar concentration of all formulations (0.02-62.5 $\mu \mathrm{mol} / \mathrm{L})$ was equivalent to the total molar concentration of free dual drugs. Similarly, PMAGP-GEM/PTX (3:1) NAG-NLCs and free GEM:PTX (3:1) were used to treat normal L929 cells for 72 hours.

\section{In vitro cellular uptake}

\section{Confocal laser scanning microscopy}

A549 cells (overexpressed glucose receptors) were used to evaluate the cellular uptake of PMAGP-GEM/PTX NAGNLCs (3:1) and PMAGP-GEM/PTX NLCs (3:1). Cells were seeded in six-well plates at a density of $2 \times 10^{5}$ cells/well. Then, cells were cultured with different FITC-labeled samples at total drug concentrations of 10 and $20 \mu \mathrm{mol} / \mathrm{L}$, respectively. After incubation for 1,2 , and 4 hours at $37^{\circ} \mathrm{C}$ or $4^{\circ} \mathrm{C}$, paraformaldehyde was used to fix cells and Hoechst $33342(10 \mathrm{mg} / \mathrm{mL})$ used to stain cell nuclei. Confocal laser scanning microscopy (CLSM) images of cells were acquired via confocal microscopy (TCS SPE; Leica Microsystems, Wetzlar, Germany). In the competition experiments, $2 \mathrm{mg} / \mathrm{mL}$ NAG was applied to A549 cells for 2 hours before NAG-NLCs were added.

\section{Flow cytometry}

Quantitative determination of cellular uptake was performed with flow cytometry (Epics XL; Beckman Coulter, Brea, CA, USA). Briefly, A549 cells were plated in six-well plates and treated with FITC-labeled PMAGP-GEM/PTX NAG-NLCs (3:1) and PMAGP-GEM/PTX NLCs (3:1) at total drug concentrations of 5, 10, and $20 \mu \mathrm{mol} / \mathrm{L}$. Untreated cells acted as controls. At corresponding time intervals (1, 2, and 4 hours) at $37^{\circ} \mathrm{C}$ or $4^{\circ} \mathrm{C}$, cells were detached and washed. In the competition experiments, $2 \mathrm{mg} / \mathrm{mL}$ NAG was applied and incubated with A549 cells for 2 hours before NAG-NLCs were added.

\section{Statistical analysis}

All data are expressed as mean \pm standard deviation. We used Student's $t$-test and analysis of variance, and $P<0.05$ indicated significant differences. 


\section{Results and discussion}

\section{Synthesis and characterization of PMAGP-GEM/PTX conjugates}

In this study, we synthesized PMAGP-GEM/PTX conjugates through four steps, and Scheme 2 illustrates the synthesis. The successful synthesis of conjugates and intermediates was confirmed by ${ }^{1} \mathrm{H}$ NMR (400 MHz, Figure S1). In order to introduce the two therapeutic agents with precise ratiometric control into the carrier, succinic anhydride was used as a cleavable linker between drugs and polymer.
In the synthesis of $2^{\prime}$-succinyl-PTX (Scheme 2), no free PTX was found by TLC detection after 3 hours of reaction. It has been reported that complete reaction of the hydroxyl group occurs in position $2^{\prime}-\mathrm{OH}$ instead of $7^{\prime}-\mathrm{OH}$ under mild conditions. $^{32}$ Multiple peaks within $2.4-2.75$ ppm might have been the absorption of the hydrogen in the - $\mathrm{CO}-$ $\mathrm{CH}_{2}-\mathrm{CH}_{2}-\mathrm{CO}-$ (conjugated PTX with succinic anhydride) (Figure S1), in accordance with the succinylation that took place preferentially at 2 -OH. In the synthesis of $2^{\prime}$-succinylGEM (Scheme 2), the hydrochloride salt of GEM avoided the partial derivatization of the amino group. Furthermore,

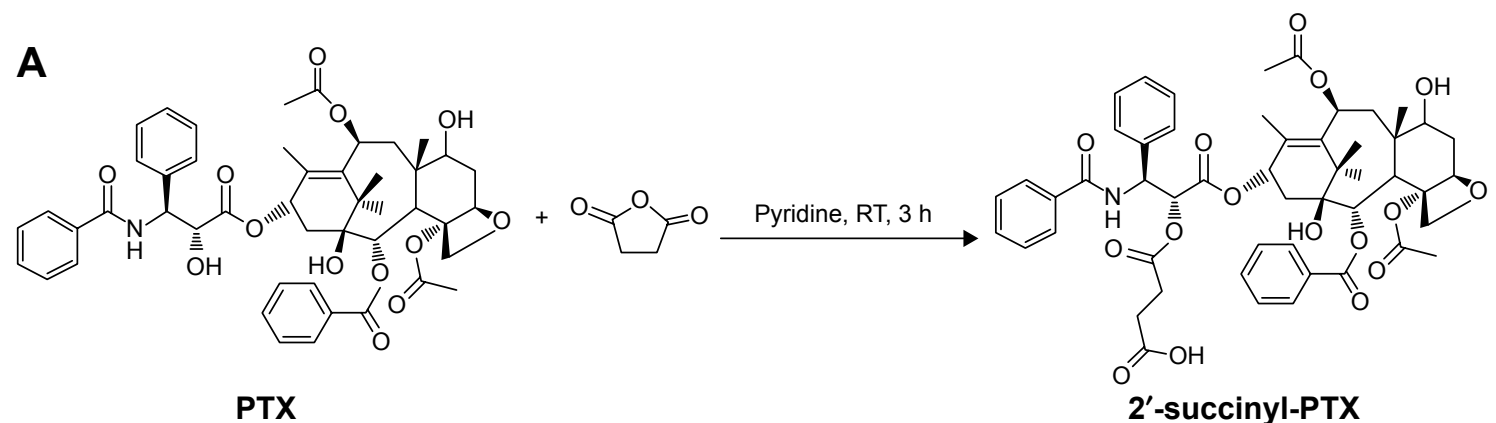

B

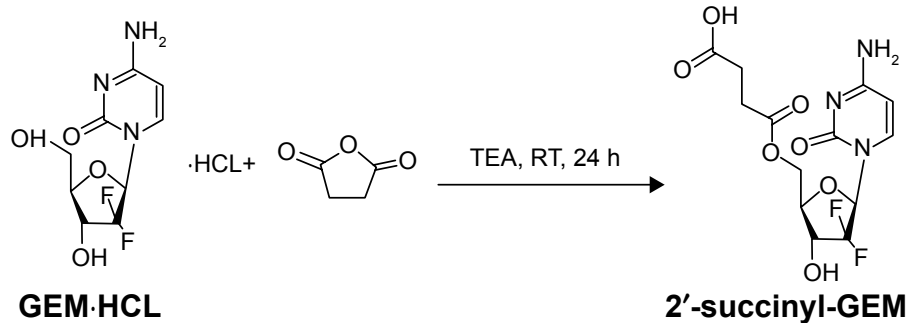

C
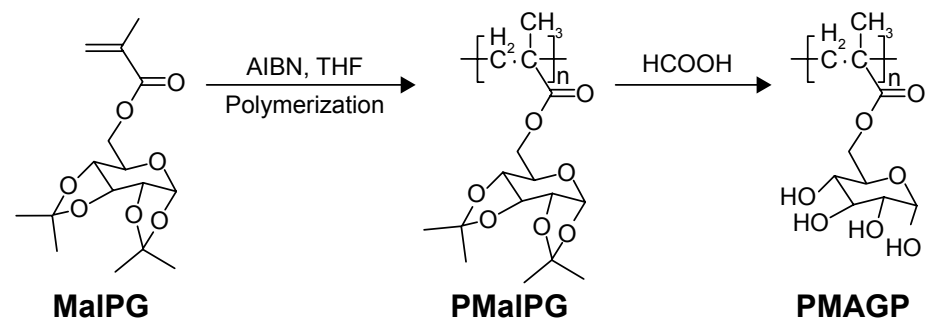

D
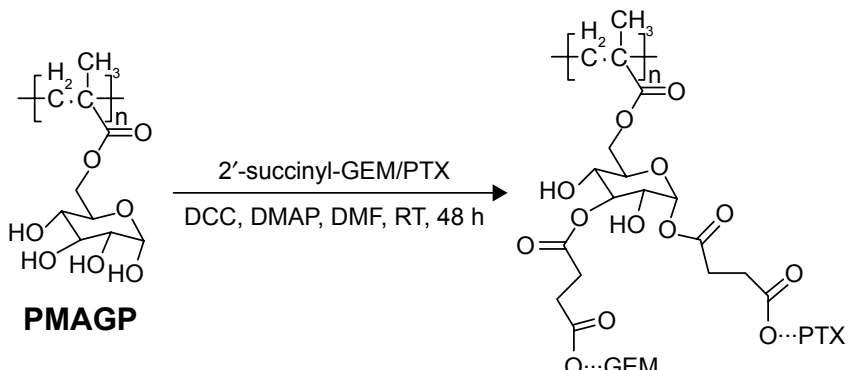

Scheme 2 Synthesis routes of PMAGP-GEM/PTX conjugates.

Notes: (A) PTX is conjugated with succinic anhydride through 2'-OH. (B) GEM is conjugated with succinic anhydride through hydroxyl group rather than amino group. (C) The copolymer PMaIPG was synthesized via RAFT polymerization technique and deprotected with methanoic acid. (D) $2^{\prime}$-succinyl-PTX must be fully reflected before 2'-succinyl-GEM added.

Abbreviations: PMAGP, poly(6-O-methacryloyl-D-galactopyranose); MalpG, 6-O-methacryloyl-I,2;3,4-di-O-isopropylidene-D-galactopyranose; PMalPG, poly(6-Omethacryloyl-I,2;3,4-di-O-isopropylidene-D-galactopyranose); GEM, gemcitabine; PTX, paclitaxel; RT, reaction time; TEA, triethylamine; AlBN, azobisisobutyronitrile; THF, tetrahydrofuran; DCC, dicyclohexylcarbodiimide; DMAP, dimethylaminopyridine; DMF, dimethylformamide; RAFT, reversible addition-fragmentation chain-transfer polymerization. 
the mild reaction conditions avoided forming a bifunctional derivative (one molecule of GEM and two of anhydrides). ${ }^{33}$ The multiple peaks at 2.55-2.7 ppm might have been the protons of $-\mathrm{CO}-\mathrm{CH}_{2}-\mathrm{CH}_{2}-\mathrm{CO}-($ Figure $\mathrm{S} 1)$. This further confirmed that succinyl-GEM conjugation occurred via ester formation. ${ }^{1} \mathrm{H}$ NMR spectra of PMAGP-GEM/PTX showed new signals at 7.4-8.2 ppm (PTX phenyl ring) and 9-9.5 ppm (GEM $\left.{ }^{4} \mathrm{C}-\mathrm{NH}_{2}\right)$. Characteristic peaks of GEM and PTX were observed in PMAGP-GEM/PTX conjugates, manifesting the synthesis of the dual-drug conjugate. TLC analysis during the synthesis of PMAGP-GEM/PTX conjugates (Scheme 2) indicated nearly 100\% conversion of monomers to polymers. What is more, $2^{\prime}$-succinyl-PTX had to be fully reflected before $2^{\prime}$-succinyl-GEM was added, because the steric hindrance of PTX would hinder conjugation with 2 '-succinyl-GEM.

Gel-permeation chromatography confirmed the synthesis of PMAGP-GEM/PTX conjugates (Figure S2). There was a single and sharp peak in the chromatography curve of PMAGP, with MW of 7,500 Da and polydispersity of 1.17. The weight-average MW of PMAGP-GEM/PTX conjugates was 17,000 Da. Polydispersity was 1.26.

\section{Fabrication and characterization of NLCs before and after drug loading}

PMAGP-GEM/PTX NAG-NLCs and blank PMAGP

NAG-NLCs were obtained using emulsification and solvent evaporation. Particle size, polydispersity index, and $\zeta$-potential of NLCs were determined by DLS measurements and are summarized in Table S1. The results showed that $\zeta$-potentials were all approximately $-27 \mathrm{mV}$ for all NLCs after production. The negative surface charge was probably one of the factors that prolonged the circulation time of NLCs for reduced clearance by the reticuloendothelial system. ${ }^{34-36}$ As shown in Figure 1, the blank PMAGP NAG-NLCs had a narrow distribution with a hydrodynamic radius of $117.5 \pm 4 \mathrm{~nm}$, and the size of the PMAGP-GEM/PTX NAGNLCs was $120.3 \pm 1.3 \mathrm{~nm}$, without significant differences. In addition, there was no obvious size change in PBS and 10\% FBS-containing $\mathrm{PBS}$ at $37^{\circ} \mathrm{C}$ over 36 hours, which indicated suitability for systemic applications in vivo. Morphologies of NLCs were measured by transmission electron microscopy, and the images revealed that all NLCs possessed uniformly spherical morphology.

\section{Ratiometric control over dual-drug loading}

To examine dual-drug loading in NP systems, we varied the 2 '-succinyl-GEM:2'-succinyl-PTX molar ratios. Results showed that the GEM and PTX loaded in NLCs were in keeping with the initial 2'-succinyl-GEM:2'-succinyl-PTX molar ratios (Table 1). These results prove that this method can encapsulate various types of drugs with convertible ratios.

\section{In vitro cytotoxicity assay and biocompatibility study}

In vitro cytotoxicity analysis of blank PMAGP NAG-NLCs

The biocompatibility of blank PMAGP NAG-NLCs was evaluated using MTT assays. A549, NCLH1299, LTEPa2, and L929 cell lines were utilized. As shown in Figure 2A, cell viabilities were all above $90 \%$ for the different cell types treated with the blank PMAGP NAG-NLCs at all the tested concentrations up to $600 \mu \mathrm{g} / \mathrm{mL}$ after 72 hours' incubation, indicating that the blank PMAGP NAG-NLCs had excellent biocompatibility and safety.

In vitro cytotoxicity analysis of different formulations In vitro cytotoxicity analysis of PMAGP-GEM/PTX NAGNLCs (different formulations) and free drugs (different formulations) against A549 cells was conducted by MTT assays, and results are shown in Figure 2B and C. After 72 hours' incubation, all formulations showed dose-dependent cell proliferation-inhibition behavior.

It has been reported that the dose ratio affects the combination effect, ${ }^{37}$ and synergistic effects can be induced in certain cases of combinatorial drug delivery. ${ }^{38,39}$ To investigate the combination effect of the codelivery system, A549 cells were treated with PMAGP-GEM/PTX NAG-NLCs (different formulations) and free drugs (different formulations). Table 2 shows the $\mathrm{IC}_{50}$ and $\mathrm{CI}_{50}$ values of different formulations. CI values higher than, equal to, or lower than 1 indicate antagonism, additivity, or synergism, respectively. ${ }^{34}$ On the whole, $\mathrm{IC}_{50}$ and $\mathrm{CI}_{50}$ values of all PMAGP-GEM/PTX NAG-NLCs with different molar ratios were lower than those of the free-drug cocktail. This can be explained by the enhanced uptake of NLCs relative to free drugs. Similar cases have been previously reported..$^{40-42}$ In contrast, no synergistic effect was observed in the cocktail, as shown in Table 2, indicating the NLCs we designed had pronounced synergy and were evidently superior. ${ }^{43}$

Furthermore, the lowest $\mathrm{IC}_{50}$ value of $0.64 \pm 0.24 \mu \mathrm{M}$ was discovered in the PMAGP-GEM/PTX (3:1) NAG-NLC group, and the lowest $\mathrm{CI}_{50}$ value of 0.414 was also in the PMAGP-GEM/PTX (3:1) NAG-NLC group. Therefore, the PMAGP-GEM/PTX (3:1) NAG-NLC group displayed the greatest cytotoxicity effect and the best synergy in all formulations. 
A

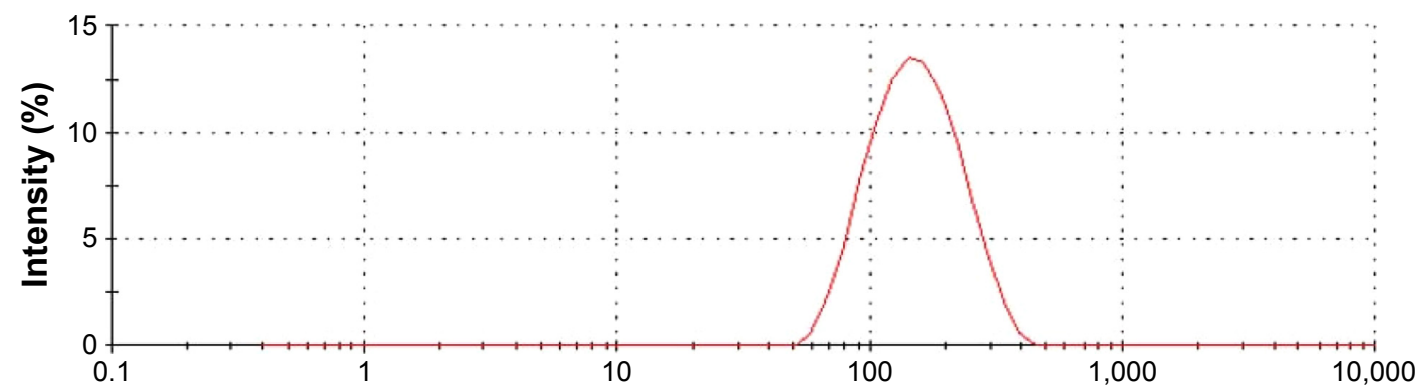

B
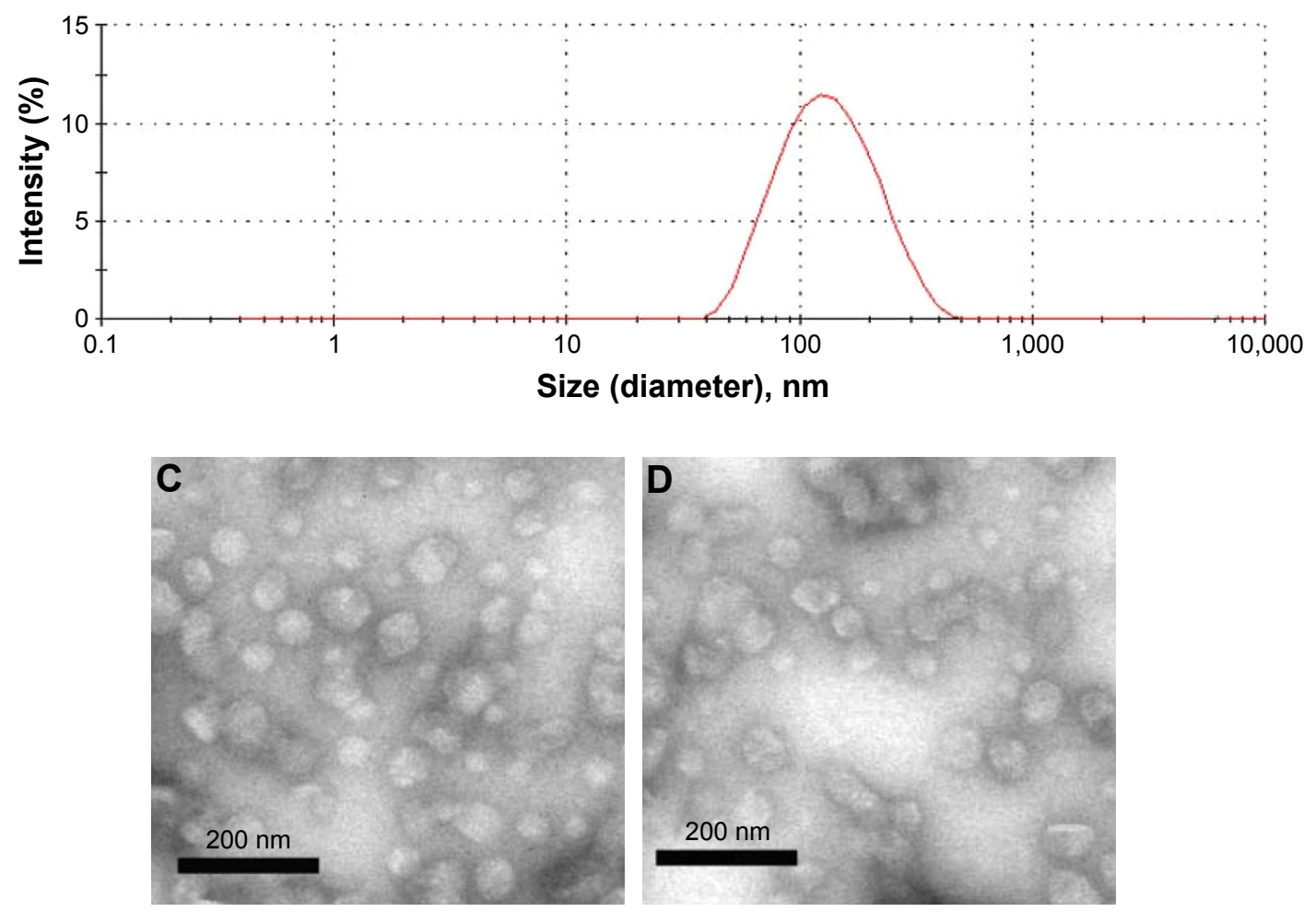

E

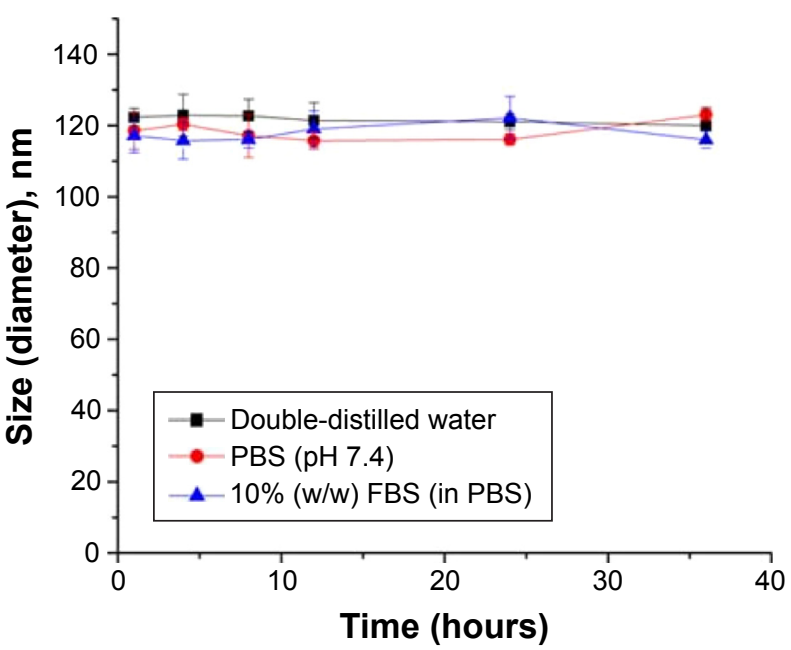

Figure I Characterization and stability study of the NLCs.

Notes: Hydrodynamic radii of PMAGP-GEM/PTX NAG-NLCs (A) and blank PMAGP NAG-NLCs (B) estimated by DLS; typical TEM images of PMAGP-GEM/PTX NAG-NLCs (C) and blank PMAGP NAG-NLCs (D). (E) Stability studies of PMAGP-GEM/PTX NAG-NLCs in double-distilled water, PBS, and I0\% FBS (in PBS). Data are expressed as mean \pm SD $(n=3)$.

Abbreviations: NLCs, nanostructured lipid carriers; PMAGP, poly(6-O-methacryloyl-D-galactopyranose); GEM, gemcitabine; PTX, paclitaxel; NAG, N-acetyl-D-glucosamine; DLS, dynamic light scattering; TEM, transmission electron microscopy; PBS, phosphate-buffered saline; FBS, fetal bovine serum; SD, standard deviation. 
Table I Characteristic features of the dual drugs in PMAGPGEM/PTX NAG-NLCs

\begin{tabular}{llll}
\hline GEM:PTX molar ratio & $\mathbf{5 : I}$ & $\mathrm{I}: \mathrm{I}$ & $\mathrm{I}: 3$ \\
\hline GEM $(\mu \mathrm{mol})$ & $19.5 \pm 0.02$ & $12.9 \pm 0.0 \mathrm{I}$ & $6.24 \pm 0.02$ \\
PTX $(\mu \mathrm{mol})$ & $3.9 \pm 0.008$ & $14.46 \pm 0.0 \mathrm{I}$ & $17.46 \pm 0.08$ \\
\hline
\end{tabular}

Notes: Data are determined via double-wavelength ultraviolet spectrophotometry and provided as mean \pm standard deviation $(n=3)$. In all cases, particle size $(n m)$ I 20.3 \pm I.3, particle polydispersity index $0.233 \pm 0.04$, and particle $\zeta$-potential $(\mathrm{mV})$ $-27.8 \pm 3.4$.

Abbreviations: PMAGP, poly(6-O-methacryloyl-D-galactopyranose); GEM, gemcitabine; PTX, paclitaxel; NAG, N-acetyl-D-glucosamine; NLCs, nanostructured lipid carriers.

\section{Benefits of drug coencapsulation}

In order to prove the advantage of PMAGP-GEM/PTX NAG-NLCs, we added a treatment of A549, NCLH1299, and LTEPa2 cells with Combo NPs (blends of two kinds of NLCs, each loading only one drug), at GEM:PTX $=3: 1$. As shown in Figure 2D-F, contrasted with others, the PMAGP-GEM/PTX (3:1) conjugate-loaded NAG-NLC system showed the highest toxicity in all three cell types. Particularly in A549 cells, the $\mathrm{CI}_{50}$ of free GEM:PTX (3:1) was calculated to be 1.895 , and that for Combo NPs (3:1) was 2.111, which demonstrated that the two formulations did not receive an efficient synergistic effect (Table 2). However, the poly-GEM/PTX (3:1) NPs showed an obvious synergism effect and the $\mathrm{CI}_{50}$ value was $\sim 0.414$, providing further proof that NAG-NLCs can induce synergy by combining both drugs into a single NP. ${ }^{34}$ Overall, combining both drugs into a single NP can lead to pronounced synergy in anticancer activity, but the mechanism is not clear. ${ }^{34,44}$ Synergism in combination therapy requires specific analysis, and partly depends on many factors, such as the pharmacokinetic activities of the individual drugs and toxicological effects. Furthermore, the results of drug combinations depend mainly on such factors as the dosing cycle and combination ratio. Therefore, more research will be needed for copackaged drugs and separately packaged drugs.

Furthermore, a similar trend was found in these three cell lines that NAG-NLCs had significantly increased cytotoxicity over untargeted NLCs. These results proved that the targeting ligand NAG was attached on the surface of NLCs, and PMAGP-GEM/PTX NAG-NLCs (containing NAG) targeted cancer cells obviously. As the sodium deoxycholate was added as an ion surfactant in the preparation of NLCs, the targeting ligand NAG attached on the surface of NLCs might
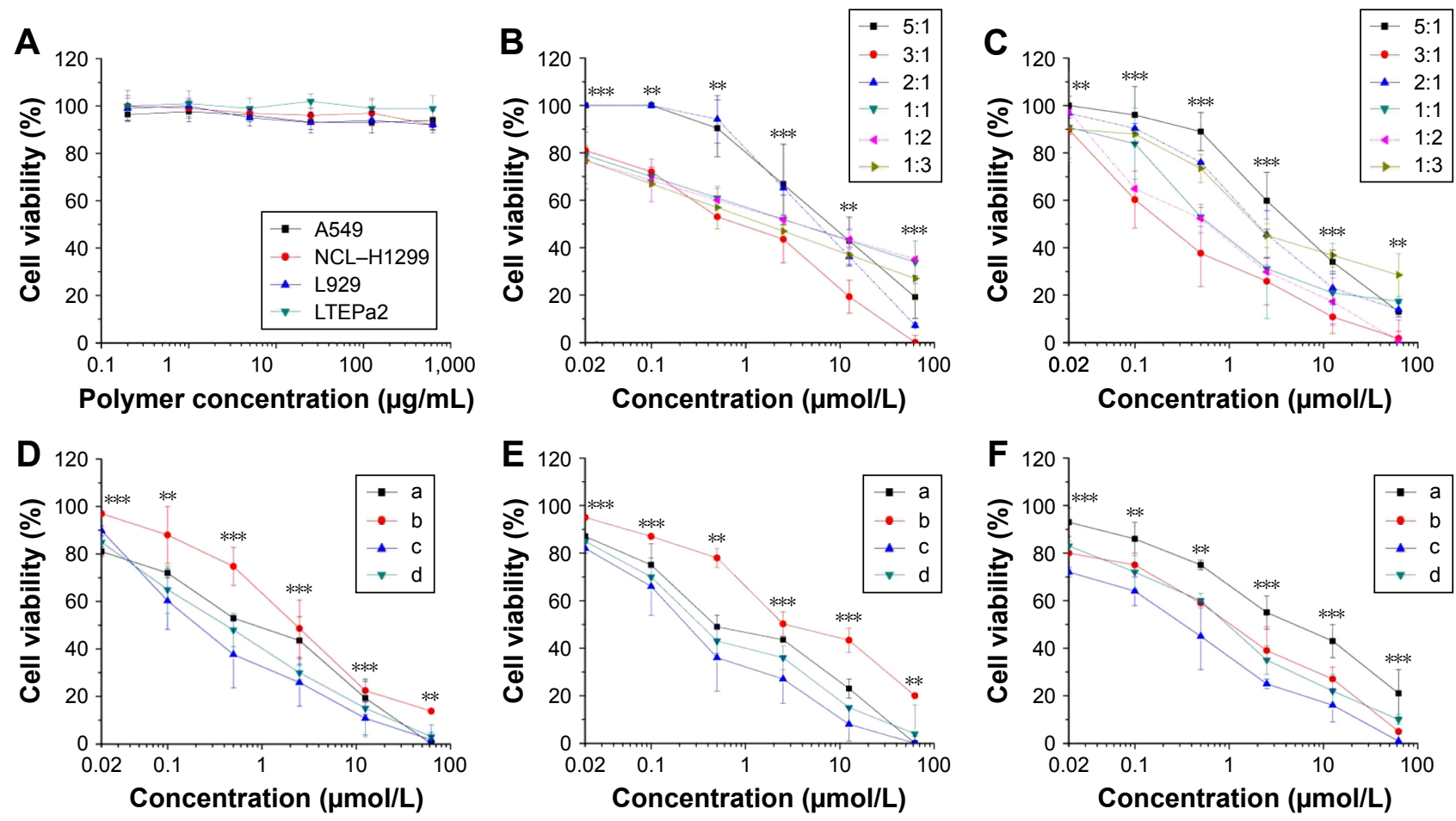

Figure 2 The biocompatibility study of empty NLCs and in vitro cytotoxicity assay of different formulations.

Notes: (A) Cell viability of different cell types after treated with empty NLCs in vitro. A549, L929, NCIHI299, and LTEPa2 were incubated with blank PMAGP NAG-NLCs for 72 hours before MTT assay $(n=6)$. (B) In vitro cytotoxicity of six molar ratios (5:I, 3:I, 2: I, I: I, I:2, and I:3) of free GEM and free PTX formulations against A549 cells for 72 hours. (C) In vitro cytotoxicity of six molar ratios (5:I, 3:I, 2:I, I:I, I:2, and I:3) of PMAGP-GEM/PTX NAG-NLCs against A549 cells for 72 hours. In vitro cytotoxicity against A549 cells (D), NCLHI299 (E), and LTEPa2 (F) for 72 hours: free GEM:PTX (3:1)-loaded NAG-NLCs (a), PMAGP-GEM NAG-NLCs + PMAGP-PTX NAG-NLCs (combo nanoparticles) (3:I)-loaded NAG-NLCs (b), PMAGP-GEM/PTX (3:I) conjugate-loaded NAG-NLCs (c), and PMAGP-GEM/PTX (3:I) conjugate-loaded NLCs (d). Data are presented as mean $\pm S D(n=6)$. $* * P<0.01 ; * * * P<0.001$.

Abbreviations: NLCs, nanostructured lipid carriers; PMAGP, poly(6-O-methacryloyl-D-galactopyranose); NAG, N-acetyl-D-glucosamine; GEM, gemcitabine; PTX, paclitaxel; $\mathrm{SD}$, standard deviation. 
Table $2 \mathrm{IC}_{50}$ and $\mathrm{Cl}_{50}$ of different formulations in $\mathrm{A} 549$ cells

\begin{tabular}{|c|c|c|}
\hline Formulation & $I_{50}(\mu M)$ & $\mathrm{Cl}_{50}$ \\
\hline Free GEM & $4.97 \pm 0.234$ & - \\
\hline Free PTX & $0.5 I \pm 0.036$ & - \\
\hline Free GEM:PTX (5:I) & $6.52 \pm 0.164$ & 3.229 \\
\hline Free GEM:PTX (3:I) & $2.95 \pm 0.221$ & 1.895 \\
\hline Free GEM:PTX (2:1) & $5.8 \pm 0.683$ & 4.576 \\
\hline Free GEM:PTX (I:I) & $3.4 I \pm 0.034$ & 3.68 \\
\hline Free GEM:PTX (I:2) & $3.49 \pm 0.27$ & 4.806 \\
\hline Free GEM:PTX (I:3) & $1.523 \pm 0.166$ & 2.317 \\
\hline PMAGP-GEM/PTX (5:I) NAG-NLCs & $2.168 \pm 1.51$ & 1.07 \\
\hline PMAGP-GEM/PTX (3:I) NAG-NLCs & $0.64 \pm 0.24$ & 0.414 \\
\hline PMAGP-GEM/PTX (2:I) NAG-NLCs & $1.26 \pm 0.23$ & 0.995 \\
\hline PMAGP-GEM/PTX (I:I) NAG-NLCs & $0.75 I \pm 0.18$ & 0.814 \\
\hline PMAGP-GEM/PTX (I:2) NAG-NLCs & $0.67 \pm 0.22$ & 0.92 \\
\hline PMAGP-GEM/PTX (I:3) NAG-NLCs & $0.975 \pm 0.09$ & 1.485 \\
\hline Combo NPs* (3:I) & $3.29 \pm 0.181$ & 2.111 \\
\hline
\end{tabular}

Notes: Data are expressed as mean \pm SD. *PMAGP-GEM NAG-NLCs + PMAGPPTX NAG-NLCs.

Abbreviations: $\mathrm{IC}_{50}$, half-maximal inhibitory concentration; $\mathrm{Cl}_{50}$, combination index ( $50 \%$ cell kill); GEM, gemcitabine; PTX, paclitaxel; NLCs, nanostructured lipid carriers; PMAGP, poly(6-O-methacryloyl-D-galactopyranose); NAG, N-acetyl-D-glucosamine; $\mathrm{SD}$, standard deviation; NPs, nanoparticles.

have been caused by the hydrogen bond formed between NAG and sodium deoxycholate.

In vitro cytotoxicity analysis of PMAGP-GEM/PTX (3:I) NAG-NLCs and free GEM:PTX (3:I) against normal cells

The normal mouse fibroblast cell line L929 was used to estimate the toxicity of PMAGP-GEM/PTX(3:1)NAG-NLCs and free GEM:PTX (3:1) on normal cells. As shown in Figure 3A, cell viability of PMAGP-GEM/PTX (3:1) NAG-NLCs and free GEM:PTX (3:1) against L929 was all above 60\%, which was much higher than A549 (Figure 2). This phenomenon had previously been observed for another system. ${ }^{40}$

\section{Release of GEM and PTX from PMAGP- GEM/PTX conjugate-loaded NLCs}

In vitro GEM- and PTX-release kinetics from PMAGP-GEM/ PTX (3:1) conjugate-loaded NAG-NLCs at $\mathrm{pH} 6$ and $\mathrm{pH} 7.4$ were quantified by high-performance liquid chromatography. As shown in Figure 3B, sustained drug release patterns at different $\mathrm{pH}$ values were obtained for both GEM and PTX, and GEM released more quickly than PTX at early time points. This might be because GEM is substantially smaller than PTX, which can cause less steric hindrance toward hydrolysis. In sharp contrast, the release of the two drugs was obviously affected by environmental acidity, and the release rate at pH 7.4 was markedly slower than at pH 6 (Figure 3B). To some extent, this was due to the drugs being linked through a hydrolyzable ester bond, and the hydrolysis rate at neutral $\mathrm{pH}$ is slower than at acidic $\mathrm{pH}$, despite the drugs being hydrolyzed in both $\mathrm{pH}$ conditions. Acid-facilitated release is beneficial for acidic tumor environments. ${ }^{45}$

\section{In vitro cellular uptake}

\section{Confocal laser scanning microscopy}

Cellular uptake of FITC-labeled NLCs and FITC-labeled NAG-NLCs was visually determined using CLSM. Cellular
A

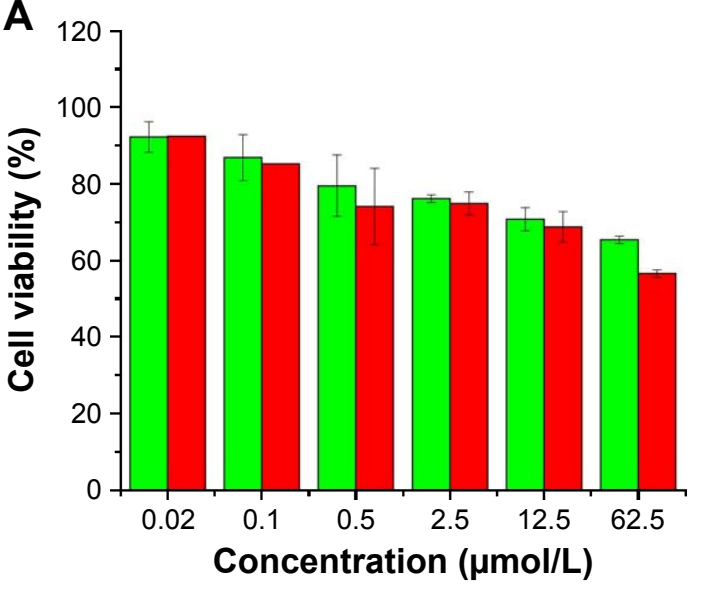

PMAGP-GEM/PTX (3:1) NAG-NLCs

Free GEM:PTX (3:1)

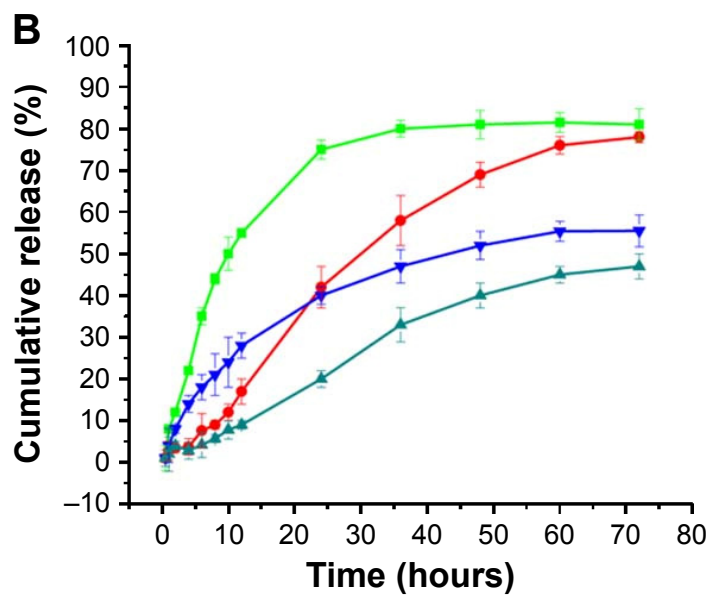

$\because$ GEM release at $\mathrm{pH} 6 \rightarrow \mathrm{PTX}$ release at $\mathrm{pH} 6$ GEM release at $\mathrm{pH} 7.4 \multimap \mathrm{PTX}$ release at $\mathrm{pH} 7.4$

Figure 3 In vitro cytotoxicity assay against normal cells and in vitro drug release study.

Notes: (A) Cytotoxicity of PMAGP-GEM/PTX (3:I) NAG-NLCs and free GEM:PTX (3:I) against normal cell line L929 cells for 72 hours. Data are presented as mean \pm SD $(n=6)$. (B) Drug release profiles of PTX and GEM from PMAGP-GEM/PTX (3:1) conjugate-loaded NAG-NLCs at pH 6 and pH 7.4 in PBS containing $0.1 \%$ (w/v) Tween 80 at $37^{\circ} \mathrm{C}$. Data are presented as mean $\pm S D(n=3)$.

Abbreviations: PMAGP, poly(6-O-methacryloyl-D-galactopyranose); GEM, gemcitabine; PTX, paclitaxel; NAG, N-acetyl-D-glucosamine; NLCs, nanostructured lipid carriers; SD, standard deviation; PBS, phosphate-buffered saline. 
nuclei were stained with Hoechst 33342 (blue), and PMAGPGEM/PTX (3:1) was labeled with FITC (green) for subcellular observation. Figure 4 shows that green fluorescence appeared in the cells after 1 hour's incubation, and distributed broadly in the cytoplasm and cell nucleus after 4 hours, suggesting that cellular uptake of NAG-NLCs was enhanced. This confirms that NAG-NLCs can internalize rapidly through receptor-mediated endocytosis.

As shown in Figure 4, after 1, 2, or 4 hours' incubation under the different drug concentrations, the fluorescence was greener in cells treated with NAG-NLCs than with NLCs, which indicated that our targeted NPs targeted cells overexpressing glucose-receptors and then entered the cells more rapidly than untargeted NPs. The results revealed that codelivered NAG-NLCs exhibited a high level of cell uptake through endocytosis.

\section{Flow cytometry}

Flow-cytometry analysis was conducted to quantify intracellular accumulation. Figure $5 \mathrm{~A}$ and $\mathrm{B}$ show that FITC fluorescence intensity of A549 cells incubated with NAGNLCs or NLCs increased with time at the two concentrations, indicating the drug accumulated inside the cells kept a time-dependent pattern. Figure 5C and D shows the mean fluorescence intensity (MFI) of A549 cells exposed to different concentrations of NAG-NLCs and NLCs. This was consistent with the data of CLSM, ie, the MFI of A549 cells treated with NAG-NLCs was much higher than cells treated with NLCs at each time or concentration point. This is just more proof that the uptake of NAG-NLCs can be improved by receptor-mediated endocytosis. Therefore, NAG-NLCs could be more likely to treat glucose receptor-positive cancer.

\section{In vitro targeting analysis of NAG-NLCs}

To confirm further that the target-specific endocytosis of FITC-labeled NAG-NLCs was mediated by receptors, the addition of free-NAG and low-temperature variables was made. As shown in Figure 6, MFI was decreased obviously more than the untreated group when A549 cells were pretreated with $2 \mathrm{mg} / \mathrm{mL}$ NAG for 2 hours. Noticeably,

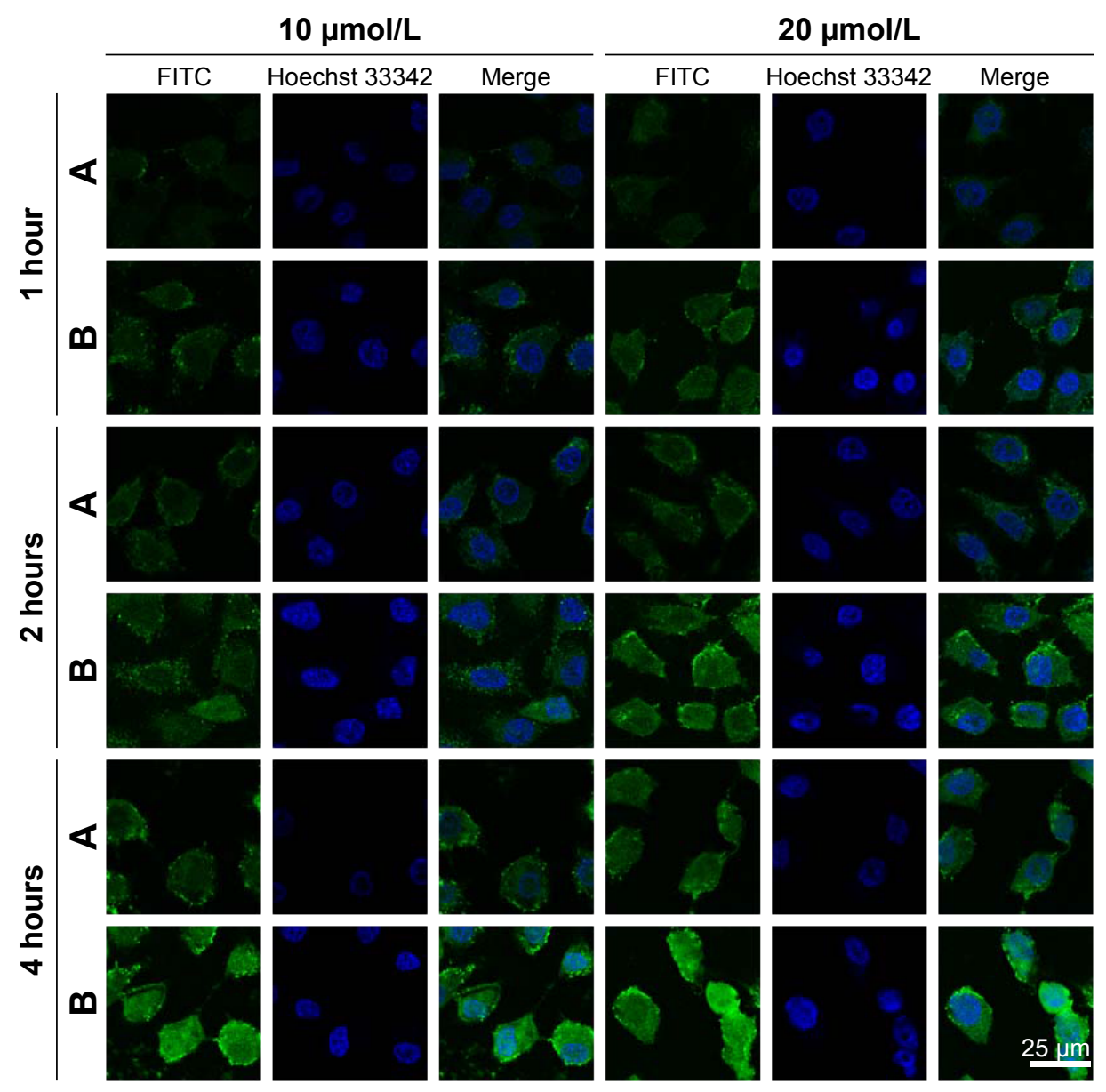

Figure 4 Confocal laser scanning microscopy images of A549 cells.

Notes: After incubation with FITC-labeled PMAGP-GEM/PTX (3:1) NLCs (A) and FITC-labeled PMAGP-GEM/PTX (3:I) NAG-NLCs (B).

Abbreviations: FITC, fluorescein isothiocyanate; PMAGP, poly(6-O-methacryloyl-D-galactopyranose); GEM, gemcitabine; PTX, paclitaxel; NLCs, nanostructured lipid carriers; NAG, N-acetyl-D-glucosamine. 

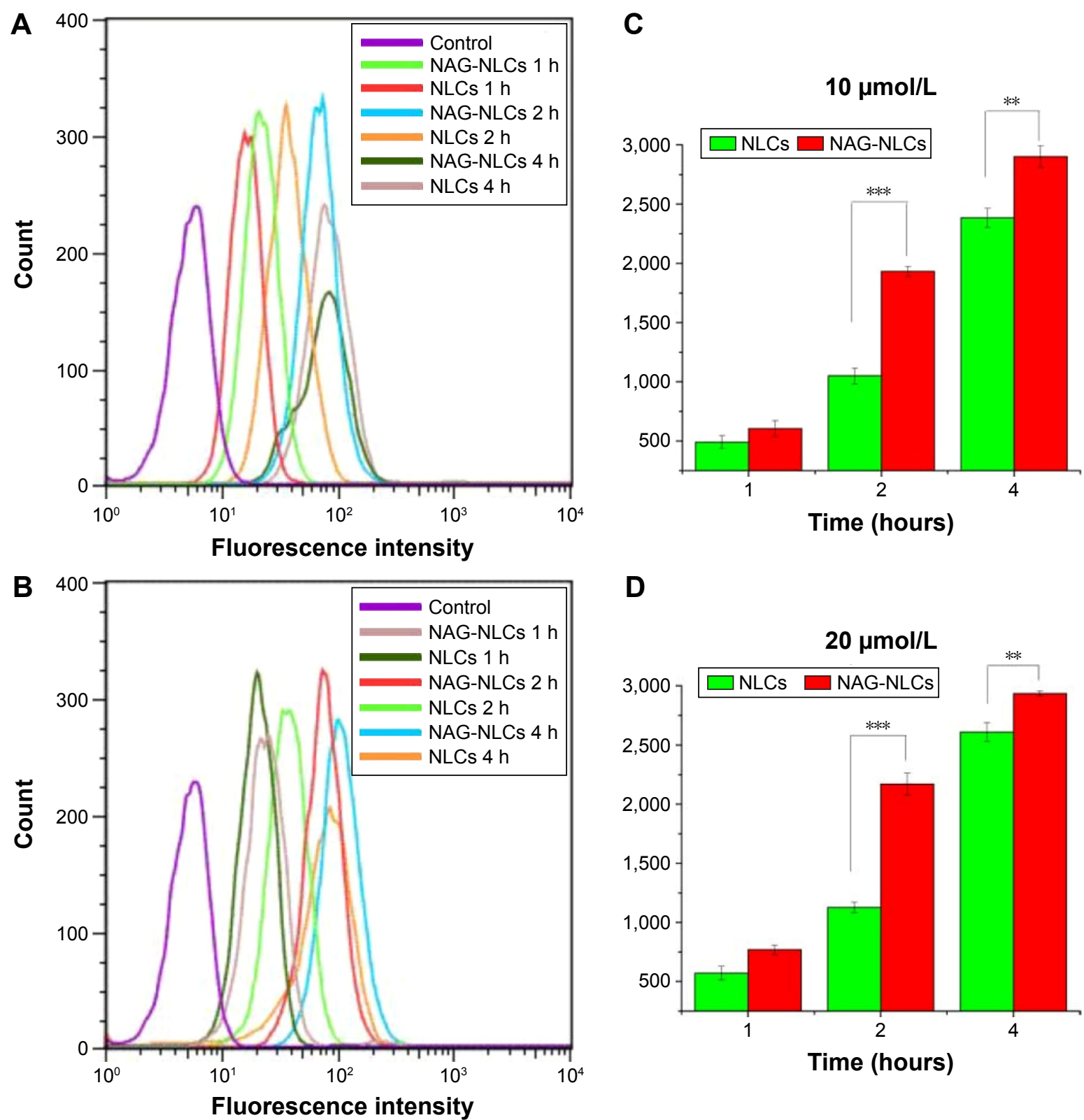

D

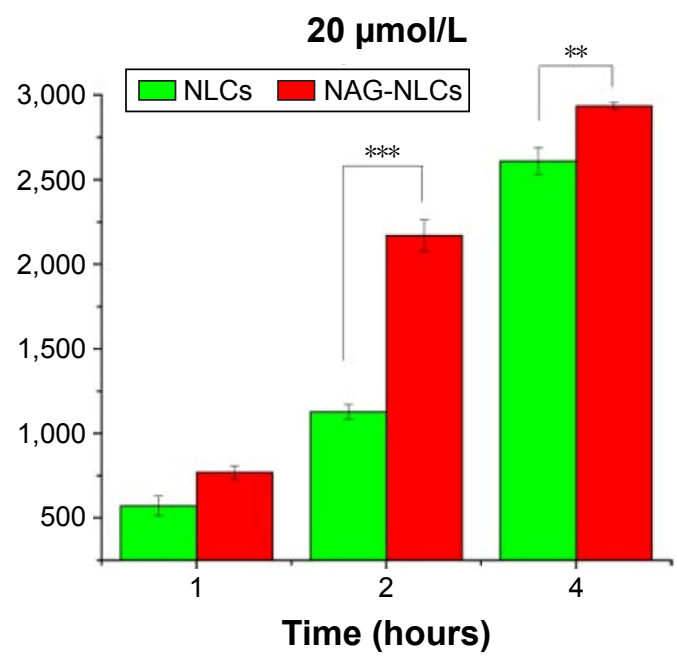

Figure 5 Cell uptake of PMAGP-GEM/PTX (3:I) NAG-NLCs and PMAGP-GEM/PTX (3:1) NAG in A549 cells analyzed by flow cytometry.

Notes: A549 cells were exposed to NAG-NLCs and NLCs with different concentrations for different time intervals. Cells incubated with only media as control. Mean fluorescence intensities show FITC intensity inside A549 cells incubated with 10 (C) and 20 (D) $\mu \mathrm{mol} / \mathrm{L}$, and flow-cytometry analysis (A and B) corresponds to the mean fluorescence-intensity results. Data presented as mean $\pm S D(n=3)$. $* * P<0.01 ; * * *<<0.00$ I.

Abbreviations: PMAGP, poly(6-O-methacryloyl-D-galactopyranose); GEM, gemcitabine; PTX, paclitaxel; NAG, N-acetyl-D-glucosamine; NLCs, nanostructured lipid carriers; FITC, fluorescein isothiocyanate; SD, standard deviation.

cellular uptake of NAG-NLCs was markedly inhibited at $4^{\circ} \mathrm{C}$. This was due to receptor-mediated uptake related to ATP-dependent endocytosis, which is relatively inactive at low temperatures. Therefore, cellular uptake by free NAG or at low temperatures was remarkably inhibited, indicating that endocytosis of NAG-NLCs was mainly mediated by receptors. In addition, competition experiments were also investigated using CLSM, as shown in Figure 6, and the result agreed with that of flow cytometry.

\section{Conclusion}

In the present study, we successfully synthesized PMAGPGEM/PTX conjugates as model hydrophilic/hydrophobic dual-drug conjugates with ratiometric control. The resulting drug conjugates can be easily loaded into NLCs for combinatorial drug delivery. The novel NLCs had an average size of $120.3 \pm 1.3 \mathrm{~nm}$ and a low polydispersity index of $0.233 \pm 0.04$. These dual drug-loaded NAG-NLCs exhibited precise drug ratiometric control. Cytotoxicity assays showed NAG-NLCs 

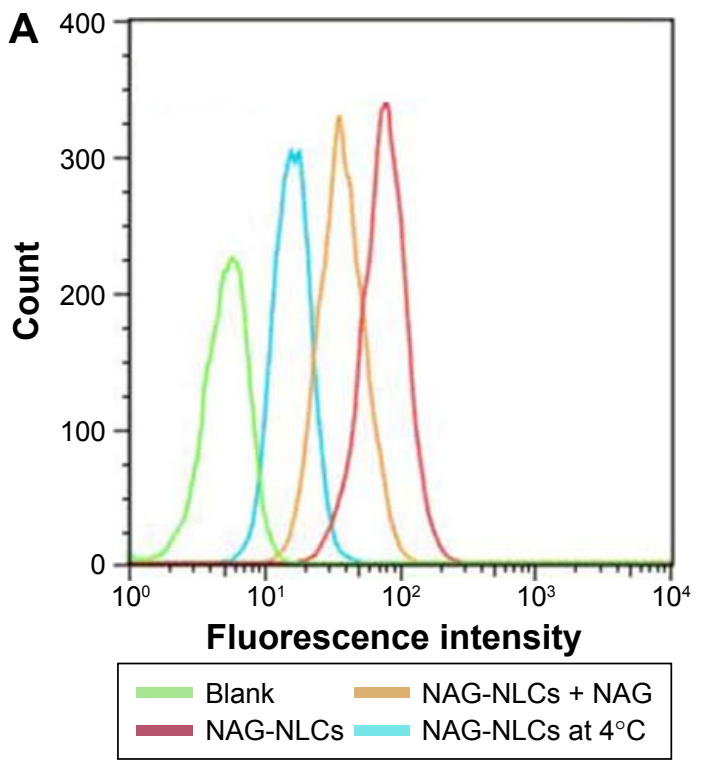

C
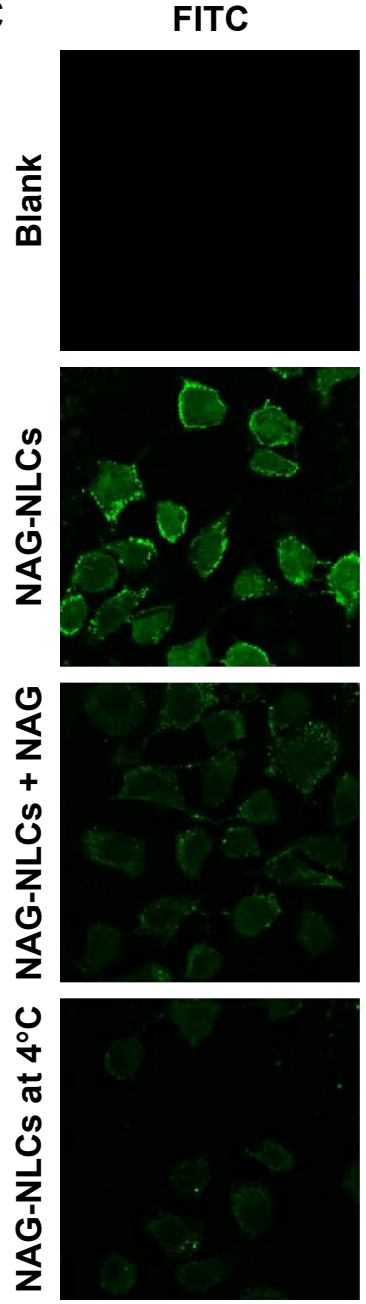

B

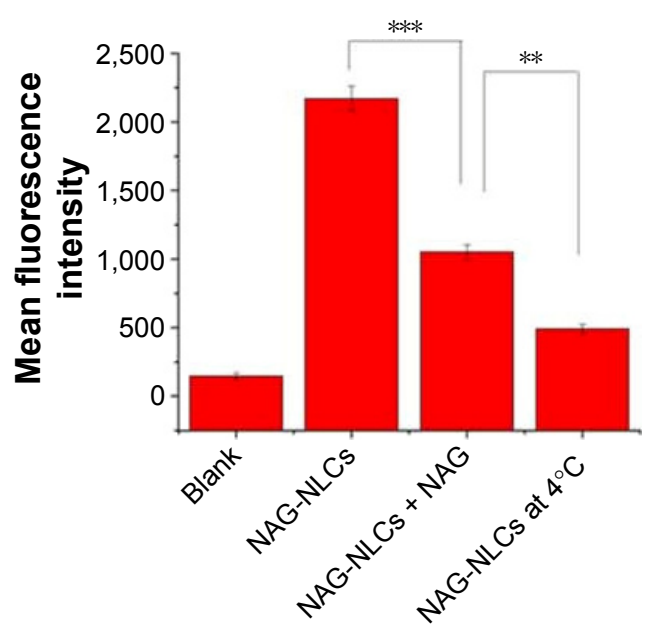

Hoechst 33342
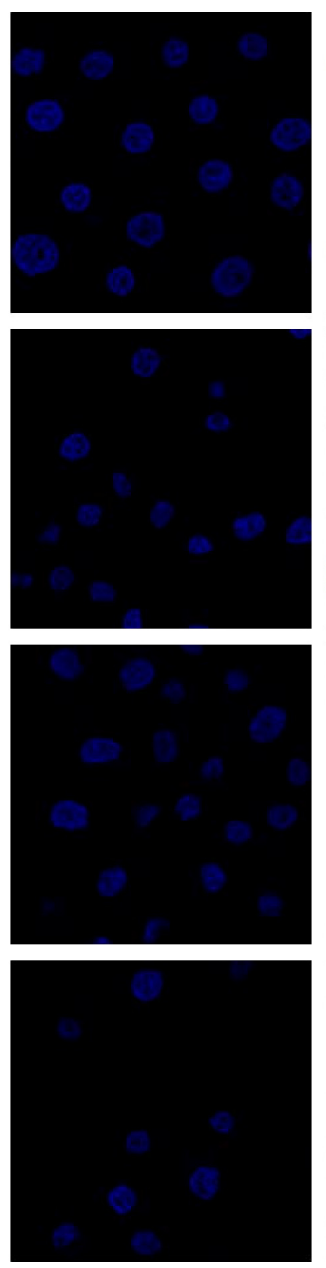

Merge
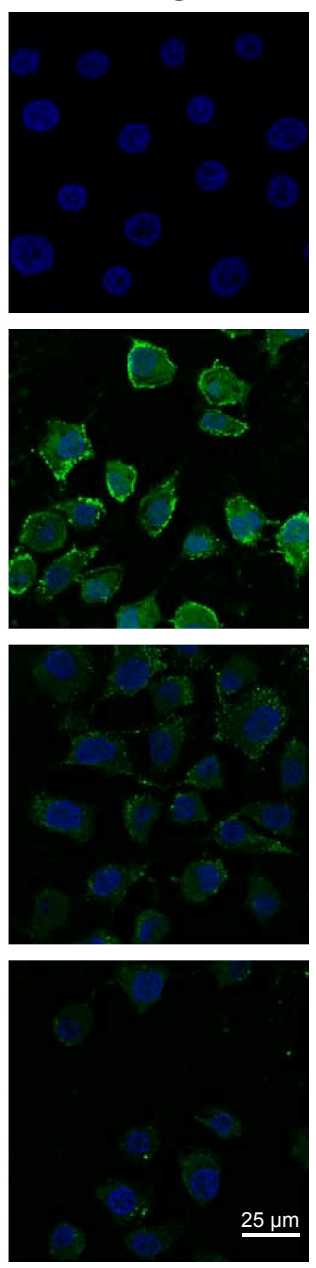

Figure 6 The competition experiments of glucose-receptor.

Notes: Blank cells, cells with FITC-labeled PMAGP-GEM/PTX (3:I) NAG-NLCs (NAG-NLCs), cells preincubated with NAG before the addition of FITC-labeled PMAGPGEM/PTX (3:I) NAG-NLCs (NAG-NLCs + NAG), and cells with FITC-labeled PMAGP-GEM/PTX (3:I) NAG-NLCs kept at $4^{\circ} \mathrm{C}$ (NAG-NLCs at $\left.4^{\circ} \mathrm{C}\right)$ in A549 cells were analyzed by flow cytometry $(\mathbf{A}, \mathbf{B})$ and confocal laser scanning microscopy $(\mathbf{C})$. $n=3$. $* * P<0.01 ; * * * P<0.001$.

Abbreviations: FITC, fluorescein isothiocyanate; PMAGP, poly(6-O-methacryloyl-D-galactopyranose); GEM, gemcitabine; PTX, paclitaxel; NAG, N-acetyl-D-glucosamine; NLCs, nanostructured lipid carriers. 
exhibited dramatic antitumor activity on non-small-cell lung cancer cells compared with normal cells. Furthermore, the PMAGP-GEM/PTX NAG-NLCs exhibited superior toxicity compared with other formulations in this study, and can achieve highly synergistic combinational chemotherapies. Remarkably, the results also showed that there was an optimum ratio of dual drugs with the best cytotoxicity effect and greatest combinatorial effects among other tested formulations. Meanwhile, in vitro targeting studies showed that NAG-NLCs exhibited higher uptake efficiency in A549 cells via glucose receptor-mediated endocytosis. The PMAGPGEM/PTX NAG-NLCs we designed can be beneficial to tumor therapy, and future research should be encouraged to investigate a dose-dependent response and optimal doses with maximal anticancer efficacy but fewer side effects.

\section{Acknowledgments}

This work was financially supported by the Shandong Provincial Natural Science Foundation (ZR2014HM096, ZR2014HQ069, ZR2014HL104) and the Project of Health Science and Technology Development Program in Shandong Province (2014WS0484).

\section{Disclosure}

The authors report no conflicts of interest in this work.

\section{References}

1. Ding Y, Qiao Y, Wang M, et al. Enhanced neuroprotection of acetyl11-keto- $\beta$-boswellic acid (AKBA)-loaded O-carboxymethyl chitosan nanoparticles through antioxidant and anti-inflammatory pathways. Mol Neurobiol. 2016;53(6):3842-3853.

2. Hashem FM, Al-Sawahli MM, Nasr M, Ahmed OA. Custom fractional factorial designs to develop atorvastatin self-nanoemulsifying and nanosuspension delivery systems: enhancement of oral bioavailability. Drug Des Devel Ther. 2015;9:3141-3152.

3. Mancarella S, Greco V, Baldassarre F, Vergara D, Maffia M, Leporatti S. Polymer-coated magnetic nanoparticles for curcumin delivery to cancer cells. Macromol Biosci. 2015;15(10):1365-1374.

4. Shi F, Zhao Y, Firempong CK, Xu X. Preparation, characterization and pharmacokinetic studies of linalool-loaded nanostructured lipid carriers. Pharm Biol. 2016;54(10):2320-2328.

5. Zhou J, Zhou D. Improvement of oral bioavailability of lovastatin by using nanostructured lipid carriers. Drug Des Devel Ther. 2015;9:5269-5275.

6. Wu M, Fan Y, Lv S, Xiao B, Ye M, Zhu X. Vincristine and temozolomide combined chemotherapy for the treatment of glioma: a comparison of solid lipid nanoparticles and nanostructured lipid carriers for dual drugs delivery. Drug Deliv. 2016;23(8):2720-2725.

7. Song A, Su Z, Li S, Han F. Nanostructured lipid carriers-based flurbiprofen gel after topical administration: acute skin irritation, pharmacodynamics, and percutaneous absorption mechanism. Drug Dev Ind Pharm. 2015;41(9):1488-1492.

8. Zhang C, Peng F, Liu W, et al. Nanostructured lipid carriers as a novel oral delivery system for triptolide: induced changes in pharmacokinetics profile associated with reduced toxicity in male rats. Int J Nanomedicine. 2014;9:1049-1063.
9. Han F, Yin R, Che X, et al. Nanostructured lipid carriers (NLC) based topical gel of flurbiprofen: design, characterization and in vivo evaluation. Int J Pharm. 2012;439(1):349-357.

10. Song J, Fan X, Shen Q. Daidzein-loaded nanostructured lipid carriersPLGA nanofibers for transdermal delivery. Int J Pharm. 2016;501(1): $245-252$.

11. Liu X, Wang Z, Feng R, Hu Y, Huang G. A novel approach for systematic delivery of a hydrophobic anti-leukemia agent tamibarotene mediated by nanostructured lipid carrier. J Biomed Nanotechnol. 2013; 9(9):1586-1593.

12. Ranpise NS, Korabu SS, Ghodake VN. Second generation lipid nanoparticles (NLC) as an oral drug carrier for delivery of lercanidipine hydrochloride. Colloids Surf B Biointerfaces. 2014;116:81-87.

13. Gu X, Zhang W, Liu J, et al. Preparation and characterization of a lovastatin-loaded protein-free nanostructured lipid carrier resembling high-density lipoprotein and evaluation of its targeting to foam cells. AAPS PharmSciTech. 2011;12(4):1200-1208.

14. Baykara M, Coskun U, Berk V, et al. Gemcitabine plus paclitaxel as second-line chemotherapy in patients with advanced non-small cell lung cancer. Asian Pac J Cancer Prev. 2012;13(10):5119-5124.

15. Kroep JR, Smit EF, Giaccone G, et al. Pharmacology of the paclitaxelcisplatin, gemcitabine-cisplatin, and paclitaxel-gemcitabine combinations in patients with advanced non-small cell lung cancer. Cancer Chemother Pharmacol. 2006;58(4):509-516.

16. Shord SS, Faucette SR, Gillenwater HH, et al. Gemcitabine pharmacokinetics and interaction with paclitaxel in patients with advanced non-small-cell lung cancer. Cancer Chemother Pharmacol. 2003;51(4):328-336.

17. Fogli S, Danesi R, De Braud F, et al. Drug distribution and pharmacokinetic/pharmacodynamic relationship of paclitaxel and gemcitabine in patients with non-small-cell lung cancer. Ann Oncol. 2001; 12(11):1553-1559.

18. Miao L, Guo S, Zhang J, Kim WY, Huang L. Nanoparticles with precise ratiometric co-loading and co-delivery of gemcitabine monophosphate and cisplatin for treatment of bladder cancer. Adv Funct Mater. 2014;24(42):6601-6611.

19. Kroep JR, Giaccone G, Tolis C, et al. Sequence dependent effect of paclitaxel on gemcitabine metabolism in relation to cell cycle and cytotoxicity in non-small-cell lung cancer cell lines. Br J Cancer. 2000; 83(8):1069-1076.

20. Tardi PG, Dos Santos N, Harasym TO, et al. Drug ratio-dependent antitumor activity of irinotecan and cisplatin combinations in vitro and in vivo. Mol Cancer Ther. 2009;8(8):2266-2275.

21. Duan X, Xiao J, Yin Q, et al. Smart pH-sensitive and temporalcontrolled polymeric micelles for effective combination therapy of doxorubicin and disulfiram. ACS Nano. 2013;7(7):5858-5869.

22. Ding Y, Han J, Tian B, et al. Hepatoma-targeting and $\mathrm{pH}$-sensitive nanocarriers based on a novel D-galactopyranose copolymer for efficient drug delivery. Int J Pharm. 2014;477(1):187-196.

23. Pawar S, Vavia P. Glucosamine anchored cancer targeted nanovesicular drug delivery system of doxorubicin. J Drug Target. 2016; 24(1):68-79.

24. Macheda ML, Rogers S, Best JD. Molecular and cellular regulation of glucose transporter (GLUT) proteins in cancer. J Cell Physiol. 2005; 202(3):654-662.

25. Pawar SK, Vavi P. Efficacy interactions of PEG-DOX-N-acetyl glucosamine prodrug conjugate for anticancer therapy. Eur J Pharm Biopharm. 2015;97(Pt B):454-463.

26. Pawar SK, Badhwar AJ, Kharas F, Khandare JJ, Vavia PR. Design, synthesis and evaluation of $\mathrm{N}$-acetyl glucosamine (NAG)PEG-doxorubicin targeted conjugates for anticancer delivery. Int $J$ Pharm. 2012;436(1):183-193.

27. Gu X, Zhang W, Liu J, et al. Preparation and characterization of a lovastatin-loaded protein-free nanostructured lipid carrier resembling high-density lipoprotein and evaluation of its targeting to foam cells. AAPS PharmSciTech. 2011;12(4):1200-1208. 
28. Cavallaro G, Licciardi M, Caliceti P, Salmaso S, Giammona G. Synthesis, physico-chemical and biological characterization of a paclitaxel macromolecular prodrug. Eur J Pharm Biopharm. 2004;58(1): 151-159.

29. Cavallaro G, Licciardi M, Salmaso S, Caliceti P, Gaetano G. Folatemediated targeting of polymeric conjugates of gemcitabine. Int J Pharm. 2006;307(2):258-269.

30. Wang Y, Hong CY, Pan CY. Galactose-based amphiphilic block copolymers: synthesis, micellization, and bioapplication. Biomacromolecules 2013;14(5):1444-1451.

31. Chou TC. Theoretical basis, experimental design, and computerized simulation of synergism and antagonism in drug combination studies. Pharmacol Rev. 2006;58(3):621-681.

32. Deutsch HM, Glinski JA, Hernandez M, et al. Synthesis of congeners and prodrugs -3 : water-soluble prodrugs of taxol with potent antitumor activity. J Med Chem. 1989;32(4):788-792.

33. Guo ZW, Gallo JM. Selective protection of $2^{\prime}, 2^{\prime}$-difluorodeoxycytidine (gemcitabine). J Org Chem. 1999;64(22):8319-8322.

34. Lv S, Tang Z, Li M, et al. Co-delivery of doxorubicin and paclitaxel by PEG-polypeptide nanovehicle for the treatment of non-small cell lung cancer. Biomaterials. 2014;35(23):6118-6129.

35. Lv S, Tang Z, Zhang D, et al. Well-defined polymer-drug conjugate engineered with redox and $\mathrm{pH}$-sensitive release mechanism for efficient delivery of paclitaxel. J Control Release. 2014;194:220-227.

36. Yang Q, Yang Y, Li L, et al. Polymeric nanomedicine for tumor-targeted combination therapy to elicit synergistic genotoxicity against prostate cancer. ACS Appl Mater Interfaces. 2015;7(12):6661-6673.
37. Lee SM, O’Halloran TV, Nguyen ST. Polymer-caged nanobins for synergistic cisplatin-doxorubicin combination chemotherapy. J Am Chem Soc. 2010;132(48):17130-17138.

38. Luo S, Gu Y, Zhang Y, et al. Precise ratiometric control of dual drugs through a single macromolecule for combination therapy. Mol Pharm. 2015;12(7):2318-2327.

39. Mayer LD, Harasym TO, Tardi PG, et al. Ratiometric dosing of anticancer drug combinations: controlling drug ratios after systemic administration regulates therapeutic activity in tumor-bearing mice. Mol Cancer Ther. 2006;5(7):1854-1863.

40. Krishnamurthy S, Ng VW, Gao S, Tan MH, Yang YY. Phenforminloaded polymeric micelles for targeting both cancer cells and cancer stem cells in vitro and in vivo. Biomaterials. 2014;35(33):9177-9186.

41. Yoo HS, Park TG. Biodegradable polymeric micelles composed of doxorubicin conjugated PLGA-PEG block copolymer. J Control Release. 2001;70(1):63-70.

42. Xu XY, Lu L, Zhou JP, et al. Preparation and characterization of $\mathrm{N}$-succinyl-N'-octyl chitosan micelles as doxorubicin carriers for effective anti-tumor activity. Colloids Surf B Biointerfaces. 2007; 55(2):222-228.

43. Liu Y, Fang J, Kim YJ, Wong MK, Wang P. Codelivery of doxorubicin and paclitaxel by cross-linked multilamellar liposome enables synergistic antitumor activity. Mol Pharm. 2014;11(5):1651-1661.

44. Jia J, Zhu F, Ma X, et al. Mechanisms of drug combinations: interaction and network perspectives. Nat Rev Drug Discov. 2009;8(2):111-128.

45. Tannock IF, Rotin D. Acid pH in tumors and its potential for therapeutic exploitation. Cancer Res. 1989;49(16):4373-4384. 


\section{Supplementary materials 'H NMR}

${ }^{1} \mathrm{H}$ nuclear magnetic resonance (NMR) spectra were recorded on an AM-400 spectrometer (Bruker Optik GmbH, Ettlingen, Germany) using deuterated $\mathrm{CDCl}_{3}$ or deuterated dimethyl sulfoxide $\mathrm{d}_{6}$ as the solvent.

\section{Gel-permeation chromatography}

Gel-permeation chromatography of poly(6-O-methacryloylD-galactopyranose) and poly(6-O-methacryloyl-Dgalactopyranose)-GEM/PTX conjugates were examined on a Waters 410 equipped with Waters Styragel HT6E columns.

\section{Characterization of NLCs}

The size and $\zeta$-potential of nanostructured lipid carriers (NLCs) were acquired by dynamic light scattering (Malvern Instruments, Malvern, UK). The morphology of NLCs was observed by transmission electron microscopy (JEM-1230; JEOL, Tokyo, Japan).

Drug-loaded NLCs without dialysis were placed in an Amicon Ultra centrifugal filter (molecular weight cutoff $100 \mathrm{kDa})$ and centrifuged (8,000 rpm, 20 minutes). We collected the residual liquid, and measured drug content that was not encapsulated in the NLCs. Amounts of GEM and PTX were determined by detection and calculation via double-wavelength ultraviolet spectrophotometry. ${ }^{1-3}$ The maximum absorbance of GEM was $269 \mathrm{~nm}$, while that of PTX was $227 \mathrm{~nm}$. The drug-loading efficiency of NLCs was calculated as follows:

$$
\frac{\mathrm{W}_{\text {total drug }}-\mathrm{W}_{\text {free drug }}}{\mathrm{W}_{\text {total drug }}} \times 100 \%
$$

$N$-acetyl-D-glucosamine (NAG) content in the nanoparticle suspension was measured by Schales and Schales

A

A

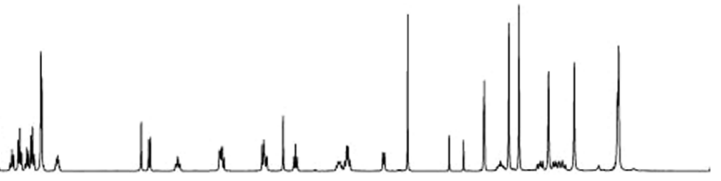

B

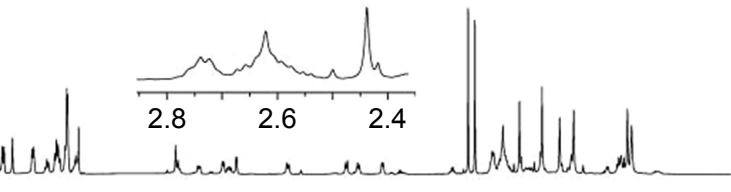

C
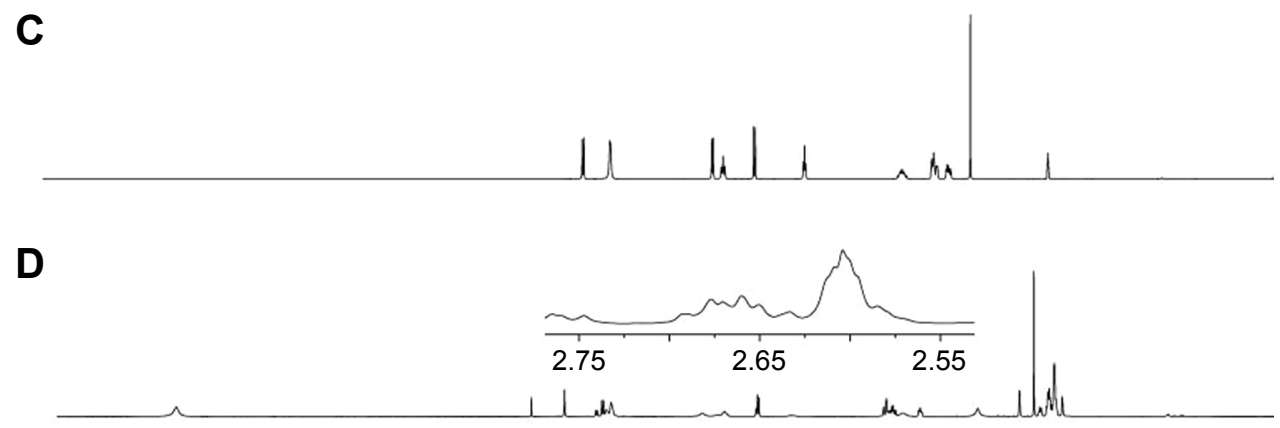

E

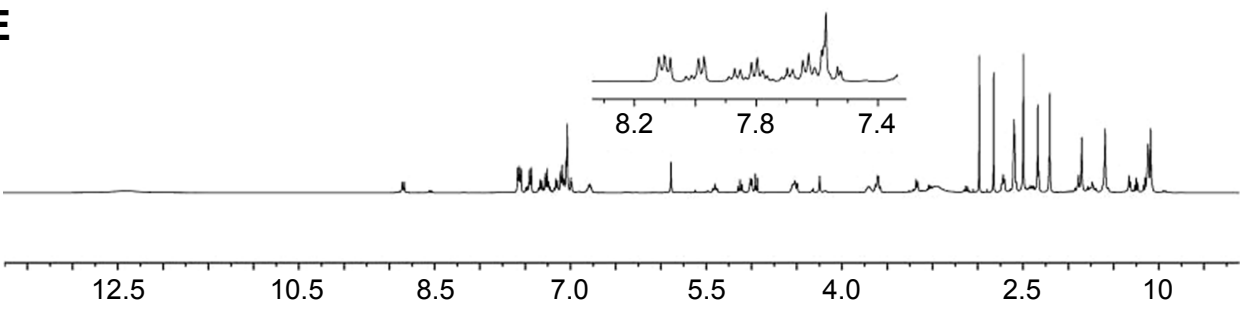

Figure SI 'H NMR spectra.

Notes: (A) PTX in DMSO-d ; (B) 2'-succinyl-PTX in CDCl ; (C) GEM HCL in DMSO-d ; (D) 2'-succinyl-GEM in DMSO-d ; (E) PMAGP-GEM/PTX conjugates in DMSO-d. Abbreviations: NMR, nuclear magnetic resonance; PTX, paclitaxel; DMSO, dimethyl sulfoxide; GEM, gemcitabine; PMAGP, poly(6-O-methacryloyl-D-galactopyranose). 
Table SI Characterization of NLCs

\begin{tabular}{lllll}
\hline Entry & Size $(\mathbf{n m})^{\mathrm{a}}$ & PDI & $\zeta$-potential $^{\mathrm{b}}(\mathbf{m V})$ & Drug-loading efficiency $^{\mathrm{c}}(\%)$ \\
\hline PMAGP-GEM/PTX NAG-NLCs $(3: 1)$ & $120.3 \pm 1.3$ & $0.233 \pm 0.04$ & $-27.8 \pm 3.4$ & 91.56 \\
Blank PMAGP NAG-NLCs & $117.5 \pm 4$ & $0.227 \pm 0.08$ & $-27.1 \pm 1.9$ & - \\
\hline
\end{tabular}

Notes: aMeasured by DLS; bestimated at ambient temperature, mean \pm SD of three measurements; 'PMAGP-GEM/PTX conjugates.

Abbreviations: NLCs, nanostructured lipid carriers; PDI, polydispersity index; PMAGP, poly(6-O-methacryloyl-D-galactopyranose); GEM, gemcitabine; PTX, paclitaxel; NAG, N-acetyl-D-glucosamine; DLS, dynamic light scattering; SD, standard deviation.

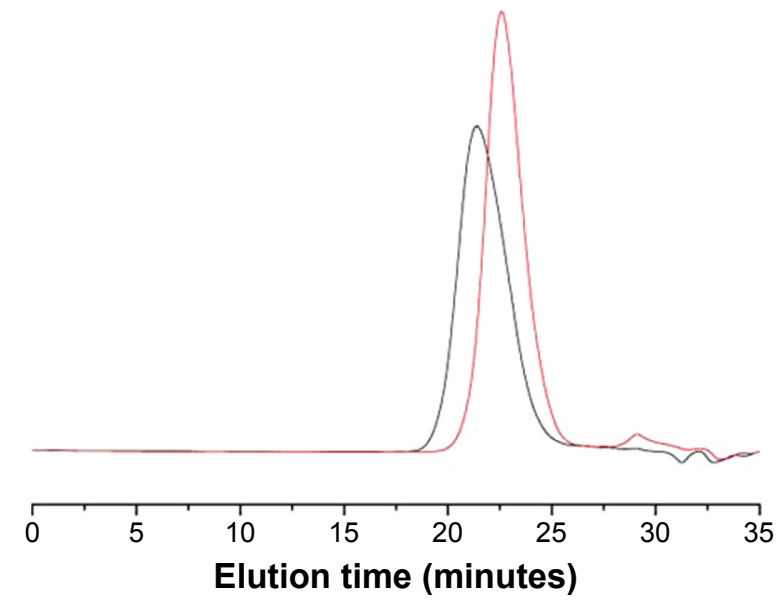

Figure S2 GPC traces of PMAGP (red) and PMAGP-GEM/PTX conjugates (blank). Abbreviations: GPC, gel-permeation chromatography; PMAGP, poly(6-Omethacryloyl-D-galactopyranose); GEM, gemcitabine; PTX, paclitaxel.

method. ${ }^{4}$ The Schales reagent was yellow, and would show color fading after reacting with reducing sugars. NAG content was detected at $420 \mathrm{~nm}$. NAG-NLCs were dissolved in methanol to release the NAG, and NLCs without NAG had no effect at $420 \mathrm{~nm}$ following the same steps. Finally, there was $48.6 \mathrm{mg}$ of NAG in the nanoparticle suspension.

\section{References}

1. Lotfy HM, Hegazy MA, Rezk MR, Omran YR. Comparative study of novel versus conventional two-wavelength spectrophotometric methods for analysis of spectrally overlapping binary mixture. Spectrochim Acta A Mol Biomol Spectrosc. 2015;148:328-337.

2. Saad AS. Novel spectrophotometric method for selective determination of compounds in ternary mixtures (dual wavelength in ratio spectra). Spectrochim Acta A Mol Biomol Spectrosc. 2015;147:257-261.

3. Bindaiya S, Bankey S, Jain D. Simultaneous determination of nitazoxanide and ofloxacin in tablet by ultraviolet spectrophotometry (dual wavelength method). Int J ChemTech Res. 2010;2(1):11-15.

4. Ferrari AR, Gaber Y, Fraaije M. A fast, sensitive and easy colorimetric assay for chitinase and cellulase activity detection. Biotechnol Biofuels. 2014;7(1):37.
International Journal of Nanomedicine

\section{Publish your work in this journal}

The International Journal of Nanomedicine is an international, peerreviewed journal focusing on the application of nanotechnology in diagnostics, therapeutics, and drug delivery systems throughout the biomedical field. This journal is indexed on PubMed Central, MedLine, CAS, SciSearch ${ }^{\circledR}$, Current Contents ${ }^{\circledR} /$ Clinical Medicine,

\section{Dovepress}

Journal Citation Reports/Science Edition, EMBase, Scopus and the Elsevier Bibliographic databases. The manuscript management system is completely online and includes a very quick and fair peer-review system, which is all easy to use. Visit http://www.dovepress.com/ testimonials.php to read real quotes from published authors. 